\title{
China's Sex Ratio and Crime: Behavioural Change or Financial Necessity? ${ }^{1}$
}

Short Title: China's Sex Ratio and Crime

\begin{abstract}
This paper uses survey and experimental data from prison inmates and comparable non-inmates to examine the drivers of rising criminality in China. We find that China's high sex ratios are associated with greater risk-taking, greater impatience and greater neuroticism amongst males. These underlying behavioural impacts explain some part of the increase in criminality. The primary avenue through which the sex ratio increases crime, however, is the direct pressure on men to appear financially attractive in order to find a partner in the marriage market. These marriage market pressures result in a higher propensity to commit financially rewarding crimes.
\end{abstract}

This paper examines the channels via which China's highly skewed sex ratio has driven recent large increases in the crime rate. Crime rates in China have increased dramatically from 7.4 per ten thousand people in 1982 to 47.8 per ten thousand in $2014 .^{2}$ At the same time, large cohorts of "surplus" males are reaching adulthood. Provincial-level data shows that crime rates are indeed higher in Chinese provinces with higher sex ratios (Edlund et al., 2013) but we do not yet have a clear understanding of the mechanism via which excess males increase crime.

In this paper we use individual survey and experimental data on male prison inmates and a comparable non-prisoner sample to examine two potential mechanisms: 1) that the increases in crime reflect behavioural impacts of growing up in a society as a young male

\footnotetext{
${ }^{1}$ We would like to thank Xiaobo Zhang for providing us with the sex ratio data. The paper also benefitted from comments from two anonymous referees and participants at the 2014 University of New South Wales Workshop in Experimental Methods for Social Science and Business; 2015 Shanghai Applied Economics Workshop at Shanghai University of Finance and Economics; 6th Workshop on the Economics of Health and Wellbeing, Melbourne, 2015; NBER-CCER Meeting at Peking University, 2015; and seminar participants at Texas A\&M and Monash University. The data set and programme that replicates the results in the paper are available alongside the paper on the Economic Journal website. Corresponding author: Lisa Cameron, Melbourne Institute of Applied Economic and Social Research, University of Melbourne, 3010, Vic., Australia. lisa.cameron@unimelb.edu.au

${ }^{2}$ Source: Zhang (2011) and Law Yearbook of China 2010-2015.
} 
surrounded by many more young males than females. Specifically, that such an environment during a young boy's formative years affects behavioural preferences, such as risk attitudes and time preferences, and personality traits; ${ }^{3}$ and 2) that the increased marriage market competition faced in adulthood as a result of the high sex ratios creates additional direct incentives for men to commit crime. Bride prices have been rising dramatically in China, with it not being unusual for families to expect the bridegroom to supply an apartment and a substantial cash gift, often amounting to a sum in the region of RMB100,000 (approximately USD $\$ 15,000) .{ }^{4}$ Men may thus resort to crime as they seek to gather the financial resources necessary to attract a mate.

Our focus is on rural-urban migrants. Rural-urban migrants constitute more than $40 \%$ of the urban labour force (NBS, 2014) and a large proportion of Chinese inmates, especially in the industrial centres in the south of the country. ${ }^{5}$ Migrants predominantly find marriage partners from their home prefecture as a result of their relative social and economic disadvantage in the cities and China's system of household registration (hukou) which limits access to services for non-locals. Hence, variation across sex ratios in home prefectures allows us to capture the effect of the extent of competition faced by individuals in the marriage market. We exploit the exogenous geographic variation in local sex ratios to identify the relationship between sex ratios and crime. Local sex ratios in China vary with the stringency with which the One Child Policy (OCP) has been implemented - which varies substantially across the country in a way that is largely orthogonal to other underlying demographic drivers, Edlund et al. (2007). We present empirical evidence supporting the exogeneity of sex ratios below.

The paper's contributions are three fold. First, it establishes that the relationship be-

\footnotetext{
${ }^{3}$ Experimental studies of other species that manipulate sex ratios of geographically concentrated populations (for example, of lizards and birds) and observe behaviour and survival rates find that high sex ratios (more men than women) increase male-to-male competition and aggression towards females, Le Galliard et al. (2005); Michler et al. (2011). Similar patterns have been described in human populations, Barber (2003); Hudson and Boer (2002) and Wilson and Daly (1985). Further, in human societies willingness to participate in risky behaviour is primarily a masculine attribute and is socially facilitate by the presence of male peers, Wilson and Daly (1985).

${ }^{4}$ See BBC Trending (2016); South China Morning Post (2016, 2017)

${ }^{5}$ In our study site of Shenzhen, $85 \%$ of inmates are rural-urban migrants.
} 
tween crime and sex ratios which was found at the aggregate (provincial) level in Edlund et al. (2013) also holds at the individual level - a male from a relatively high sex ratio prefecture with say 1.14 males to every female (our sample mean), as compared to the naturally occurring ratio of 1.07 , has an increased probability of being incarcerated for committing a crime of about 0.84 percentage points. This is a relatively large effect, corresponding to about a $34 \%$ increase in the probability of being incarcerated.

Second, the collection of individual level data, particularly experimental data, allows us to examine the behavioural mechanisms underlying this result. We show that growing up in a high sex ratio environment (more boys than girls) makes boys more risk-loving and slightly more neurotic and that this in turn makes them more likely to commit crimes in adulthood. However, this is not the only channel through which the sex ratio affects crime. A dearth of women in the marriage market further spurs single men to engage in crime in order to amass the financial resources necessary to attract a wife. The direct marriage market pressures turn out to be the more important mechanism. Consistent with financial pressure being important, we find that the high sex ratios prevailing in the current marriage market drive the propensity to commit crimes which have a high financial payoff (such as drug-dealing and theft), not violent crime.

Finally, and more generally, to the best of our knowledge this study is the first paper to examine the effect of exogenous factors on behavioural preferences and their subsequent impact on criminal behaviour. It thus makes an important contribution to our understanding of the determinants of crime.

\section{Background}

Crime rates in China have increased more than sixfold over the past three decades. Mirroring this, the arrest rate has more than doubled from 4 per ten thousand in 1988 to 8.3 per ten thousand in 2009 (Zhang et al., 2011). Major socio-economic change is undoubtedly a force behind this increase - extraordinary economic growth and rapidly rising inequality 
(Gan et al., 2013); increases in mass rural-urban migration (Zhang, 2011); and erosion of traditional values (Liu, 2005). In addition to the economic changes experienced in China over the past decades, the Chinese people have experienced dramatic change at the level of the family. China's One Child Policy was launched in 1979. This policy varied across the country but generally limited couples living in urban areas to having only one child, while most rural areas were allowed a second birth if the first was a girl. The One Child Policy, in combination with China's strong culture of son preference (particularly in rural areas), the availability of ultrasound technology and female infanticide and abandonment has resulted in a highly skewed sex ratio. By 2000 almost 120 boys were born for every 100 girls and by 2010 there were an estimated 30 million "surplus" boys (Zhu et al., 2009). ${ }^{6}$

These surplus men are pouring out of the countryside and into China's industrial cities in search of work. They are predominantly of low socioeconomic class, and concerns have been expressed that their lack of marriageability and consequent marginalization in society may lead to anti-social behaviour and violence, Hudson and Boer (2002). Young, unmarried men are the main perpetrators of crime around the world and are more likely to incur various risks - committing robbery for example - to gain the resources that may attract women, Wright (1994). More than two-thirds of violent and property crimes in China are committed by men aged between 16 and 25 years (Hu, 2006).

Although many of these rural men find their ways to China's big cities, their marriage market remains firmly in their place of birth as the hukou system limits their access to services in the cities, making them an unattractive mate. Even if they seldom visit their home town, the majority will return to find a bride or have a bride selected for them in their home region, Wei and Zhang (2011).

\footnotetext{
${ }^{6}$ The Chinese government recently relaxed the policy so that from 1st January 2016 all couples are allowed to have two children.
} 


\section{Data and Experimental Procedures}

Our data are collected in Shenzhen, a city with a population of 15 million in the southern province of Guangdong which is at the heart of China's manufacturing boom. Approximately $50 \%$ of Shenzhen's population, and $85 \%$ of inmates in the prison in Shenzhen, are rural-urban migrants. We surveyed a random sample of 959 rural-urban migrants in a male prison in Shenzhen. Of these, 734 prisoners were then randomly chosen to participate in experimental sessions. ${ }^{7}$ We also constructed, surveyed and ran experimental sessions with a representative comparison sample of 299 male non-inmate rural-urban migrant workers in Shenzhen. The sample was constructed using the sampling frame of a representative sample of internal migrants - the 2012 wave of the Rural-Urban Migration in China (RUMiC) survey. The prison takes inmates arrested in both Shenzhen and the neighbouring city of Dongguan so our migrant sample is selected to be representative (in terms of age, education and industry of employment) of the population of male migrants in these two cities, weighted by the relative size of the migrant populations in Dongguan and Shenzhen. ${ }^{8}$ Once we exclude a small number of observations with missing values (22 from the prisoner sample and 5 from the migrant sample) our final analysis sample size is 1006 - 712 prisoners and 294 non-inmate migrants.

Figures 1 and 2 compare our migrant sample with the representative RUMiC sample in Shenzhen and Dongguan. The figures shows that the age distributions in the two samples are similar. With regard to education our migrant sample has more college and university degree holders and a smaller proportion of senior high school graduates than those in the

\footnotetext{
${ }^{7}$ Fewer prisoners were selected to participate in the experiment for budgetary reasons and because of the limited time we were given to access the inmate subjects. The experiments were conducted in September 2013. We first randomly selected 1200 prisoners to be survey respondents. From these we then randomly selected 1000 to participate in the experimental sessions. We then drop the inmates in our sample that are not rural-urban migrants.

${ }^{8}$ The RUMiC project has been surveying and tracking rural-urban migrants in 15 cities in China, including Shenzhen and Dongguan, since 2008. Dongguan is another large industrial centre with 70 percent of Dongguan's population of 8 million being rural-urban migrants. The sample was recruited by the same survey company which conducted the RUMiC survey. The survey company was given the target age-educationindustry distribution of the sample. They invited RUMiC respondents, and other migrants via the internet, telephone, as well as recruiting directly from the street during November 2013.
} 
RUMiC migrant sample. ${ }^{9}$ We control for education in the empirical work. An examination of the counties from which the individuals migrate also reveals that they are drawn from similar areas (see Figure A3 in the appendix).

\subsection{Survey Questions}

The survey collected a wide array of information including demographic information, migration history (including place of birth), criminal history, and conducted personality tests. A series of questions designed to elicit time preferences were asked at the end of the questionnaire, just prior to the last module which was an IQ test. These ask the respondent to choose between getting a certain amount of money (1000 RMB which was equal to approximately USD160) in one month's time and varying amounts of money in seven months' time. More patient people will choose to defer payment even for a relatively small increase in the amount received, whereas less patient people will only choose to defer payment if the amount received increases by a substantial amount. The choices presented to participants are shown in Figure A1 in the appendix. ${ }^{10}$

The survey questions asked of the migrant sample were very similar to those asked of the inmates, except that with regard to questions about job status and living conditions we asked migrants about their current situation whereas we asked the prisoners about their situation prior to being imprisoned. These particular questions are not used in this paper.

\subsection{Administrative Data}

In addition to the survey data we have access to and are able to merge all of the prisoners' administrative records onto the survey and experimental data. The administrative data include demographic information such as age and ethnicity, hukou (residency status), and

\footnotetext{
${ }^{9}$ The sample is similar to the RUMiC sample in terms of the percentage of the sample with education above and below secondary school level which is the way the sampling frame was defined.

${ }^{10}$ Prior studies provide evidence in support of unincentivised tasks being able to elicit behavioural preferences, for example, see Gneezy et al. (2015), and questions of the type used here have been widely used to elicit time preferences.
} 
detailed information on criminal histories including types of crimes committed and current and previous sentence lengths.

\subsection{Experiments}

Both the inmate and non-inmate sample were invited to participate in a series of economics experiments. We begin with a description of the procedures in the prison and then describe how some of the procedures necessarily differed outside the prison context.

The randomly selected prisoners were told that they had been selected to participate in an experiment in which there would be the chance to earn some money. ${ }^{11}$ All participants were given the option of not participating, both before and during the experimental sessions, however no one took this option. The experiments were conducted around a week before the survey questions were administered, during the Thursday afternoon and Saturday free time periods in a large conference room. Participants were seated on separate chairs with enough space between them to avoid any communication.

Each prisoner has a prison bank account through which they receive payment for work they do while imprisoned, for example, working in the prison factory. At the conclusion of the games participants received a deposit receipt for the money which was paid into these bank accounts.

The sessions were conducted by one of the authors of this paper (Zhang) who worked with a team of 20 student research assistants from Peking University. The experiments were all conducted in Mandarin with pen and paper as in this context computerization was infeasible. Participants marked their decisions on paper forms. Each participant received a printed copy of the experimental instructions which were also read to the group as a whole. There were opportunities to ask questions and test questions were embedded to enable us to discern whether participants understood the instructions. ${ }^{12}$

\footnotetext{
${ }^{11}$ They were not given a specific estimate of how much they might earn.

${ }^{12}$ The vast majority of respondents answered the test questions correctly. Only 17 observations from the inmate sample and 7 observations from the migrant sample failed to answer the test questions correctly. These observations were dropped from the analysis.
} 
Risk Game The risk game is a standard multiple price list format game which involves a series of choices between lotteries, similar to that used in Murnighan et al. (1988). The specific choices faced by the participants are shown in Figure A2 in the appendix. Each decision involves choosing between receiving an amount with certainty (45 Yuan which was approximately US $\$ 7$ ) or a lottery with a $50 \%$ chance of receiving a larger amount and a $50 \%$ chance of receiving nothing. The "winning" amount increases as one works one's way through the choices. Relatively risk-loving individuals will prefer the lottery even if they stand to gain only a small amount if they "win", while more risk-averse individuals will switch to choosing the lottery only once the "prize" becomes sufficiently large. ${ }^{13}$ Once all participants had made their choices a participant was asked to draw a ball from a bag in which there were eleven balls numbered from 1 to 11 . The chosen ball determined which choice the participants were to be paid for. Then a different participant was asked to roll a dice which determined the outcome for those who had selected a lottery. ${ }^{14}$

The non-inmate migrants were invited to come to a downtown meeting room. The experiments were conducted in a large meeting room where game participants were seated separately. All payoffs in the risk game were multiplied by 1.5 for the migrant sample. This was done to make the stakes approximately the same value relative to the opportunity cost of time. This is the protocol typically used when conducting games across different cultural settings so as to keep the real value of the stakes as close as possible to constant across groups, Cameron et al. (2009). ${ }^{15}$ Participants were paid in cash at the end of the game.

\footnotetext{
${ }^{13}$ Participants were allowed to switch from choosing the certain sum to choosing the lottery at most only once.

${ }^{14}$ The actual payoff method was slightly more complicated than this as each participant played four games in the following order: 1) ultimatum game; 2) risk game; 3) trust game; 4) half of the sample played a dishonesty game based on Mazar et al. (2008) and Friesen and Gangadharan (2013) and half played a compliance game based on (Friesen, 2012). Participants were aware that payments would be made for only one of these games, which was selected randomly by drawing balls with number 1 to 4 from a bag. The method described above was followed if the risk game was randomly selected for payment.

${ }^{15}$ The stakes for the migrants were set in relation to their opportunity cost of time. In addition to the higher stakes paid, they were paid a show-up fee of 100 RMB. The show-up fee was paid to ensure that we were able to attract a representative sample of migrants. The average earnings in the games with the migrant population is $199.67 \mathrm{RMB}$ including the show-up fee. This is $175.2 \%$ (87.5\% if we exclude the show-up fee) of the average daily income for this group. Figure A3 shows that the distribution of place of birth in our migrant sample is very similar to the distribution in the representative sample of migrants in
} 
Otherwise, the same protocols were followed as for the inmates.

Census Data We use China's 2000 census to calculate two sex ratios - the "prevailing sex ratio" which is the ratio of men to women of prime marriageable age in each individual's prefecture of birth (18 to 27 years of age in 2013 which means they were 5 to 14 years old in 2000). This is similar to the "operational sex ratio" which is commonly used in the biological literature and is defined as the ratio of sexually competing males that are ready to mate to sexually competing females that are ready to mate. We hypothesise that the prevailing sex ratio is the most salient with respect to marriage market pressures as it reflects current general marriage market conditions which is the likely way in which people form expectations as to their marriage market prospects. ${ }^{16}$ In addition we construct "own cohort sex ratios" which are the ratio of boys to girls in the home prefecture in the individuals' (5-year) birth cohorts. We use this measure to examine the behavioural impacts of growing up in a high sex ratio environment.

A potential concern arising from the calculation of the sex ratios in the way described above is that they may be biased due to migration out of rural regions (between birth and age 14). ${ }^{17}$ However, Figure 3 shows that the prevailing sex ratio is unlikely to be biased in the RUMiC survey data, suggesting that we were able to attract a representative sample or that at least any selection was orthogonal to place of birth and hence the sex ratio. Further, the rate of unemployment in our migrant sample $(9.3 \%)$ is very similar to that amongst rural migrants in Shenzhen and Dongguan generally (8.9\%), as calculated from the RUMiC 2013 data. We used lower stakes for the prisoners as prisoners' monthly earnings in jail are very low (less than $10 \%$ of that of the non-prison migrant sample), although they also receive monetary transfers from family members. On average prisoners earn 63.5 RMB from the games which accounts for more than $60 \%$ of their average monthly earnings and $6 \%$ of the average amount held in their prison savings account. Importantly, we have since conducted the same risk games, using the same protocols, with a sample of female prisoners in China. In these games we varied the stakes used. We find that increasing or decreasing the stakes by $50 \%$ does not affect behaviour in the games (lottery choice) $(\mathrm{p}=0.63)$. Results available on request.

${ }^{16}$ We base our prevailing sex ratio on similar cohorts to the sex ratio used in Edlund et al. (2013), although theirs is at the provincial level. They use the 16-25 age group for their analysis on the basis that 16 is the age of full criminal responsibility and 25 is the upper age for juvenile crime; and that this is the most crime-prone age group, accounting for more than $70 \%$ of criminal offenders since the mid-1980s.

Note that our prevailing sex ratio remains relevant even to older men as owing to general marriage market tightness, spousal age gaps in China have been rising. It is not unusual for older men to marry significantly younger women, $\mathrm{Mu}$ and Xie (2014).

${ }^{17}$ Since the late 1990s China's rural-urban migration has gained significant momentum with the number of such migrants increasing from 39 million in 1997 to around 60 million in 2000 and further to 166 million 
this way. Using data in the Census on individuals' current place of residence and their hukou location (which reflects their place of birth), Figure 3 plots the sex ratio by age in 2000 for rural "residents" — the solid line includes only individuals who are living in their hukou location at the time of the census, and the dotted line plots the sex ratio for all individuals with rural hukou, hence, treating rural-urban migrants as if they were still living in rural areas. The figure clearly demonstrates that for those currently of prime marriageable age (5-14 years old in 2000), the 2000 sex ratio is unaffected by migration (as the gap between the solid line and the dotted line is very small). This is because there is little migration of individuals aged under $15 .^{18}$

This concern is more relevant for the "own cohort sex ratio" as it is constructed from the 2000 Census data separately for each birth cohort, including cohorts who were over the age of 15 in 2000 (over 28 in 2013). Figure 3 however shows that out-migration even in these older age cohorts is not large enough to substantially affect the sex ratio. To allay any concerns in this regard, in the work below we control for prefecture out-migration rates. Further, in unreported results we introduced an interaction term which allowed the effect of the own sex ratio to differ for those cohorts in which there was out-migration in 2000 (those aged over 15 in 2000 and so over 28 in 2013). This interaction term was however always insignificant. Results available on request.

Our total sample of 1,006 rural-urban migrants come from 162 prefectures. The prevailing sex ratios range from 1.00 to 1.49 , with a mean of 1.14 . The own cohort sex ratios range from 0.81 to 1.53 with a mean of $1.13 .^{19}$ Other prefecture level variables used below are calculated from the 2005 1\% Population Survey (except for prefecture GDP data which is taken from the City Statistical Yearbooks)

in 2015. The majority of such migrants are males.

${ }^{18}$ China's institutional restrictions on migration cause Chinese rural-urban migrants to often leave their families behind when migrating to cities to work and the Compulsory Schooling Laws makes it illegal to hire anybody under 16 years of age. Note that we are unable to calculate sex ratios at the prefecture level adding back rural-urban migrants as the hukou information is only reported at the provincial level.

${ }^{19}$ The prisoners in our sample come from 147 prefectures. The non-inmate respondents come from 105 prefectures. 


\subsection{Summary Statistics}

Table 1 compares summary statistics for the prisoner and non-inmate migrant samples. It shows that on average, the non-inmate migrant sample is of similar age to the inmates. They are, however, somewhat better educated with approximately 3 years more schooling. Their parents are also more educated than the parents of their prisoner counterparts. Non-inmate migrants are 11 percentage points more likely to be married, but have fewer children.

\section{Estimation Strategy}

We start the analysis by examining whether a higher sex ratio in one's prefecture of birth is associated with a higher propensity for criminality. ${ }^{20}$ That is, we regress whether the individual is incarcerated or not on each of the sex ratios and a range of individual and prefecture level controls.

We use a case-control approach - as we over-sample those affected by the "rare event" (in our case criminality) and supplement this with a sample from the wider population. This approach has been used widely to study events such as maternal mortality; infant mortality; and criminality. (See for example Ganatra et al. (1998), Blair et al. (1996) and Dobrin (2001).) We follow King and Zeng (2001) and correct for the use of case-control data by estimating logistic regressions when the dependent variable reflects the sampling strategy (i.e. when we are estimating whether the respondent is a prisoner or not). The estimate of the constant is corrected using the ratio of the sample size of prisoners and non-prisoners to their population size. ${ }^{21}$ All regressions presented in this paper control for sending province

\footnotetext{
${ }^{20}$ Our dependent variable reflects incarceration, and not criminality per se. The widely cited crime statistics that show crime increasing in China similarly reflect criminal convictions, rather than the number of crimes actually committed.

${ }^{21}$ We assume a prisoner population in Shenzhen of 86,148 and a migrant population of 3,450,000. Calculations underlying these assumptions are shown in Section A.1 in the appendix. This empirical strategy relies heavily on the assumption that the errors follow a logistic distribution. Xie and Manski (2010) suggest testing this assumption by estimating and comparing weighted and unweighted logistic regressions. If the errors do follow a logistic distribution, the weighted and unweighted estimates should be similar. Table A1 in the appendix presents the weighted and unweighted results and, as can be seen, they are very similar. We present the unweighted results as our main results in the body of the paper. When estimating regressions with a dependent variable that is other than whether the respondent is the prisoner, we include a dummy
} 
fixed effects and standard errors are clustered at the prefecture level.

\subsection{Exogeneity of Sex Ratios in China}

The most important concern with respect to the validity of our estimation strategy is that prefecture sex ratios may reflect cultural differences across different prefectures (for example, the extent of son preference) which are also associated with differences in behaviours, such as the propensity to commit a crime. ${ }^{22}$ Edlund et al. (2007) however show that sex ratios in China are a result of the stringency with which the One Child Policy (OCP) has been implemented. Specifically, they find that the extent of adherence to the OCP is a function of the characteristics of government officials (in particular the extent of central government contacts) at the time of the policy's introduction, and that these characteristics are not serially correlated so sex ratio at birth is unrelated to other contemporaneous outcomes. ${ }^{23}$

If cultural factors or other non-time-varying characteristics of prefectures are important determinants of sex ratios then we would expect to see time dependence in sex ratios. However data from the 2000 Census show that the correlation in the prefecture sex ratios for cohorts born before the introduction of the OCP (1971 to 1975) and five to fifteen years after the OCP (1986 to 1995) is almost zero (0.05). Hence it seems safe to assume that sex ratios in China are exogenous. Nevertheless, we explore the sensitivity of our results to potential endogeneity below. ${ }^{24}$

for the sampling strata (whether the respondent is a prisoner or not) as suggested by Solon et al. (2015).

${ }^{22}$ Dreze and Khera (2000) find that the sex ratio is strongly positively correlated with murder rates in cross-sectional district level data in India. They suggest that this may be due to endogeneity with more patriarchal districts having stronger preferences for male children and high rates of violence against women.

${ }^{23}$ If leaders who strictly enforced the OCP were also strict on crime this would threaten our identification strategy only if the leader's characteristics and policies affected current crime rates. As leader characteristics are not serially-correlated, a leader's crime policy would have to have very long-lasting effects in the order of lasting two to three decades in order to impact upon current crime levels. Edlund et al. (2007) discuss such a possibility and say they are unaware of any such policies, as are we, and conclude that it is unlikely.

${ }^{24} \mathrm{~A}$ further threat to the exogeneity of sex ratios is that they reflect both the implementation of the OCP and the the propensity of the population to commit infanticide, abandon their child and have sex-selective abortions. If the propensity to commit these acts is correlated with the propensity to engage in other crimes then the sex ratio will be endogenous. We however think that this is unlikely. Later in the paper we show that high sex ratios are associated predominantly with financial crimes. The criminology literature finds that there is little correlation between involvement in violent offending and non-violent offending (MacDonald et al., 2009). This is borne out in our prison administrative data which shows a low and insignificant 


\section{Results}

Column 1 in Panel A in Table 2 reports coefficients and marginal effects from regressing the prevailing prefecture of birth sex ratio on the probability of being incarcerated. The coefficient on the sex ratio is positive and strongly statistically significant. The estimate of the marginal effect suggests that moving from the naturally occurring sex ratio at birth in humans of about 1.07 to our sample mean of 1.14 (114 males for every 100 females) would increase the incarceration rate by about 0.21 percentage points. Given that we estimate that about 2.5 percent of the male migrant population in Shenzhen are incarcerated (see Section A.1), this corresponds to an $8.4 \%$ increase in the probability of being incarcerated for committing a crime.

In Column 2 we add additional controls for individuals' ages, marital status, number of children, years of schooling, IQ test result, and mothers' and fathers' years of schooling. Column 3 adds prefecture level controls in the regression - the log of prefecture level GDP, the gini coefficient for individual monthly income, the rate of migration out of the prefecture and the share of minority groups in the rural prefecture population. ${ }^{25}$ The only one of these prefecture level variables that is significant is the share of the population from minority ethnicities. It is positive and significant. The inclusion of the household and prefecture controls does not affect the statistical significance of the coefficient on the sex ratio. The magnitude of the marginal effect increases with the inclusion of the controls to 0.12 . This is a relatively large effect, consistent with a $34 \%$ increase in crime associated with the increase from the naturally occurring sex ratio to the sample mean.

correlation between having engaged in violent and non-violent crimes.

Another threat to identification is that our dependent variable captures incarceration, rather than criminality. If the OCP was most stringently implemented in places that were thought poorly of by urban residents, then people in high sex ratio prefectures might be discriminated against in the courts and so be more likely to be in prison. We are able to test this directly (if we assume that the effect on the intensive and extensive margins are likely to be similar) by regressing sentence length on indicators of the type of crime committed, the sex ratio and our individual and prefecture-level controls. When we do this sex ratio is not a significant determinant of sentence length.

${ }^{25}$ The gini coefficient is calculated from data on individuals' monthly incomes in the $20051 \%$ Population Sampling Survey. 
Panel B conducts the same exercise for the own cohort sex ratio. It also is positively and significantly related to the probability of being in prison. The size of the coefficient on the own cohort sex ratio is smaller in magnitude than that for the prevailing sex ratio. When we include all controls (Column 3), an increase in the own cohort sex ratio from the naturally occurring rate of 1.07 to 1.14 is associated with a 0.27 percentage point increase in crime $(11 \%)$.

Our finding of a positive and significant correlation between the sex ratio faced by individuals from different prefectures of origin and the probability of being incarcerated verifies the findings of Edlund et al. (2013) which found a positive relationship between provincial level sex ratios and crime rates for 30 provinces between 1988 and 2004. That we are able to establish the same relationship between individual propensities to commit criminal acts and sex ratios from 162 prefectures is of some note.

The other explanatory variables largely have the expected relationship with criminality. Years of schooling is negatively correlated with the probability of being incarcerated, as is mother's educational level. Being married is also negatively associated with being in prison, although prisoners on average have slightly more children than non-inmates. There is not a significant difference in the IQs of inmates and non-inmates. These results are largely consistent with the summary statistics in Table 1.

\subsection{Robustness - Potential Endogeneity of Sex Ratios}

We argued above that the sex ratio in China is exogenous because it reflects the implementation of the OCP. Nevertheless, to dispel any remaining concerns about endogeneity, Panels $\mathrm{C}$ and $\mathrm{D}$ of Table 2 present results where we instrument for the sex ratios. We use two instruments. The first is an interaction between a variable reflecting the severity of the implementation of the policy ("policy fertility") which is the average number of children per women who would be born in the prefecture if childbearing rigorously followed the prescribed fertility policy (Baochang et al., 2007) and the inverse of the ethnic minority share 
of the rural prefecture population (as ethnic minorities are not subject to the policy). The second instrument reflects the timing of the introduction of ultrasound B-scan technology the number of years prior to 2013 that an ultrasound B-scan machine was installed in the county - and is a measure of availability and familiarity with the technology that can be used to make it possible to conduct sex-selective abortions. This variable has been used in previous studies to predict sex ratios and has been found to be uncorrelated with pre-existing trends in sex ratios (Chen et al., 2013), which suggests it is a valid instrument. We similarly interact it with the inverse of the ethnic minority share. Both instruments are statistically significant predictors of both the prevailing sex ratio and the own cohort sex ratio. The coefficient on the sex ratios remain positive and statistically significant when instrumented (Panels C and D of Table 2). The coefficients increase in magnitude (for example from 0.12 in Column 3, Panel A to 0.225 in Column 3, Panel C of Table 2 for the prevailing sex ratio), suggesting that our non-instrumented results may be underestimating the effect of sex ratios on crime. The IV and OLS coefficients are however not statistically significantly different from one another. ${ }^{26}$

\subsection{Behavioural Determinants}

So what is driving the relationship between the sex ratio and crime? As discussed above, growing up in an environment with excess males may affect men's behavioural traits. Greater competition in finding a mate may also affect men's actions. Table 3 examines whether two particular behavioural measures which have been hypothesised to be related to criminality in the literature, (Becker, 1968; Gottfredson and Hisrchi, 1990) - risk taking and time preferences - are associated with the sex ratio.

\footnotetext{
${ }^{26}$ To further dispel concerns that the sex ratio may be proxying for unobservable characteristics of the prefectures we re-estimated the model including an additional array of prefecture-level controls. We include controls for the proportion of the prefecture's rural population with educational attainment of at least high school level; the proportion who are in the labour force; the unemployment rate; the proportion who have rural residency status; average log annual income; and average real gdp per capita growth between 2002 and 2012. The sex ratio remains strongly significant (at the $5 \%$ level) with a marginal effect of similar magnitude. Results are available on request.
} 
Time Preferences We construct two different indicators of time preferences from the time preference questions. Column 1 uses a continuous measure of patience as the dependent variable. This variable indicates the point at which the respondent switches from choosing to get a payoff in one month's time to getting a payoff in seven months' time. There are eleven questions. Our constructed variable ranges from 0 (most impatient - always chooses to get the money in one month's time) to 11 (most patient -always chooses to get the greater amount in the future). The dependent variable in Column 2 equals one if the individual is the most impatient (always prefers the payment in one month's time instead of seven months' time) and zero otherwise.

Risk Preferences Two analogous measures of willingness to take risks are used. Column 3 presents results using a continuous measure indicating the switching point in the risk game (the point at which the participant changes from choosing the sure payment to choosing the gamble) as the dependent variable. We have reverse-coded this variable so that a higher number indicates a greater willingness to take risks. The dependent variable in Column 4 equals one for those who always choose to take the gamble and zero otherwise.

As discussed above, to differentiate between the developmental behavioural story and the impact of prevailing marriage market conditions, we employ two different sex ratios. The "prevailing sex ratio" that we discussed above and which reflects the current marriage market and the "own cohort sex ratio" which reflects the ratio of boys to girls in the individual's prefecture of birth in his own (5 year) birth cohort. The own cohort sex ratio thus reflects the conditions in the key development period. ${ }^{27}$

The top panel of Table 3 shows that for boys growing up in an environment with many more boys than girls is very strongly associated with being more risk-loving. A 10 percentage point increase in the sex ratio in an individual's birth cohort (in the prefecture of birth) is

\footnotetext{
${ }^{27}$ Note that little is actually known about when risk and time preferences are formed. In a review of the literature Chuang and Schechter (1996) find that correlations of individual risk and time preferences across adults are significantly positive but moderate in size suggesting some stability in adulthood but less stability than that of personality traits.
} 
associated with a 5.2 percentage point increase in the probability that a respondent chooses always to take the riskiest option (significant at the $1 \%$ level). It is also associated with greater impatience, although not as strongly. Panel B presents results using the prevailing sex ratio instead of the own cohort sex ratio. Again there is a positive association with risk aversion (although less strong than for the own cohort sex ratio) and with impatience. As the two sex ratios are positively correlated (correlation coefficient of 0.58 ) it is not surprising that they show similar associations with the behavioural measures. In Panel $\mathrm{C}$ we include both sex ratios in the regressions. This shows that while the prevailing sex-ratio is associated with more risk-loving preferences in general, it is the own sex-ratio that is a stronger predictor of the riskiest behaviour (indicative of a preference for high levels of risk-taking being formed during childhood and youth). Current marriage market conditions have a stronger association with impatience. As we will see below, impatience does not affect crime once we control for other individual characteristics (as don't moderate levels of risk-taking) and the behavioural impact on crime is coming through the development of a preference for high levels of risk-taking in childhood leading to an increased propensity to engage in crime. ${ }^{28}$

Personality Traits We also collected information on the Big 5 personality traits and examine whether they are associated with sex ratios. ${ }^{29}$ These results are also reported in Table 3. None of extroversion, conscientiousness, openness and agreeableness are statistically significantly associated with either sex ratio. The own cohort sex ratio is however strongly positively associated with (relatively small) increases in the neuroticism scores. A 10 percentage point increase in the sex ratio is associated with about a 0.03 increase in the neuroticism score (which has a mean of 3.07). It remains strongly significant when the prevailing sex ratio is also included while the prevailing sex ratio loses significance $(\mathrm{p}=0.80)$. That the own cohort sex ratio has a stronger relationship with neuroticism makes sense as

\footnotetext{
${ }^{28}$ The continuous risk-loving variable is an insignificant predictor of criminality $(\mathrm{p}=0.28)$ as is the continuous patience measure $(\mathrm{p}=0.31)$.

${ }^{29}$ The Big 5 personality traits measure five broad dimensions of personality that have been found to be consistent non-overlapping measures of personalities with wide applicability across cultures. The five dimensions are openness to experience, conscientiousness, extroversion, agreeableness and neuroticism.
} 
these personality traits are generally thought to form in childhood and remain relatively stable from early adulthood, Costa and Macrae (1994).

Having found reasonably large impacts of sex ratios on behavioural preferences, we now examine how these preferences affect criminality. Table 4 presents the results. Panel A presents results without controls and Panel B includes controls. Column 1 shows the result of regressing whether one is a prisoner or not on measures of risk and time preferences. Being in the upper tail of the distributions of impatience and risk-taking is associated with a greater probability of criminality. The effects of the behavioural impacts are strongly significant and positive (although impatience becomes statistically insignificant once we add individual and prefecture controls in Panel B). The magnitude of the effect of risk-taking on criminality is relatively large. Being in the riskiest group is associated with a 1.1 percentage point (44\%) increase in the probability of being incarcerated, ceteris paribus. ${ }^{30}$

Column 2 further controls for the Big 5 personality traits. Consistent with the psychology literature, neuroticism is strongly and positively related to criminality (Egan, 2009). Our result that conscientiousness and openness are negatively associated with criminality is also largely consistent with expectations. We also find that in the Chinese context extroversion is negatively associated with crime. The magnitude of these impacts are also quite large. A $10 \%$ increase in the neuroticism score (from a mean of 3.07 ) results in a 0.6 percentage point increase $(24 \%)$ in the probability of incarceration. ${ }^{31}$

Columns 3 and 6 replicate the results from Table 2 showing that the prevailing sex ratio is strongly associated with an increased probability of being incarcerated and that the own cohort sex ratio is also positively associated with criminality but to a lesser degree. Column 4 shows that adding the behavioural measures to the regression reduces the significance of the own cohort sex ratio, consistent with the own cohort sex ratio only operating via

\footnotetext{
${ }^{30}$ The magnitude of the coefficient on the indicator of being in the most impatient group suggests a 0.4 ppt $(16 \%)$ in the probability of being an inmate but is statistically insignificant.

${ }^{31}$ The psychology literature has found that psychopathy in males is associated with lower conscientiousness and greater neuroticism (Egan, 2009). Low openness has been found to have some connection with crime but less consistently than the other traits, Wiebe (2004).
} 
these avenues. The own cohort sex ratio becomes statistically insignificant once both the behavioural measures and personality traits are included (Column 5).

Importantly, and in contrast, Columns (7) and (8) show that the prevailing sex ratio remains strongly significant when the behavioural and personality traits are included in the criminality regressions (as do the coefficients on the behavioural parameters), suggesting that there are mechanisms beyond the behavioural ones that drive the relationship between criminality and the prevailing sex ratio.

A possible concern with these results is that being in prison may affect preferences and so we may be picking up the effect of being incarcerated on preferences rather than the effect of preferences on criminality. This is less of a concern for the Big-5 personality traits which are thought to be relatively stable over time but is a greater concern for the questions on time preferences and risk attitudes. If incarceration does affect behaviour then one would expect that the length of time spent in prison would be associated with behavioural differences. We test this by adding the time spent in prison as an additional control variable in the regressions, while also controlling for total sentence length. Table A2 presents these results and shows that the coefficients on both of these variables are statistically insignificant in all estimations. Including these variables does not change the estimated effect of the sex ratio. ${ }^{32}$

Although we find quite large effects of sex ratios on behavioural preferences and of behavioural preferences on criminality, when we put these two results together - the effect of sex ratios on behavioural preferences and personality traits and the impact of these on crim-

\footnotetext{
${ }^{32}$ Another test we conduct is to allow the effect of the sex ratio on the behavioural parameters to differ depending on whether the individual is in prison or not. We do this by adding an interaction of the sex ratio with whether the individual is in prison or not in the Table 3 regressions, while also controlling for whether the individual is in prison. The interaction terms is insignificant in every specification. We also examine whether the own cohort sex ratio has a similar effect on the behavioural parameters within the prisoner sample and migrant sample and find that it does, although it is estimated less precisely within the migrant sample. Also, Birkeland et al. (2011) found that the prison environment did not drive findings drawn from a comparison of behaviour in social preference experiments of prisoners and non-prisoners in Norway. This conclusion was made on the basis of similar differences being found in a comparison of the experimental behaviour of people with a criminal record and not in prison (including fully suspended sentences) with members of the general public. One may also be concerned that the inmates migrated earlier than noninmates and have been trapped in prison since. The average sentence length is however relatively short at 6 years and our results are robust to controlling for the length of time since migration.
} 
inality - we find that a 10 percentage point increase in the own cohort sex ratio increases the probability of being incarcerated via increased risk-taking by 0.06 percentage points $(2.5 \%)$ and via increased neuroticism by an additional 0.06 percentage points (2.5\%). ${ }^{33}$ Hence, a total of 0.12 percentage points $(5.0 \%)$ increase via behavioural channels. This accounts for only about $9 \%$ of the total effect of the sex ratio on incarceration. ${ }^{34}$

\subsection{Examining Marriage Market Mechanisms}

So it appears that although the own cohort sex ratio affects underlying behavioural parameters and personality traits and these in turn affect criminality, the prevailing sex ratio continues to have a strong effect on criminality, independent of behavioural parameters and traits. The pressure high sex ratios place on men looking to find a wife has been hypothesised in the literature to be an important driver of the relationship between the sex ratio and criminality. There is pressure on men to make themselves more financially attractive in order to find a mate in a world in which there are many more men than women. Although the financial pressures of raising a family are not insignificant, they are not as intense as those associated with building the one-off burdensome payment required to secure a bride which often runs to tens of thousands of dollars. This hypothesis has however not been directly tested. $^{35}$

If the prevailing sex ratio is capturing what people perceive to be marriage market pressures, then its effect should be strongest for unmarried men. To examine this mechanisms we

\footnotetext{
${ }^{33}$ These figures are calculated using the marginal effects of the own cohort sex ratio on preferences and traits in Table 3 and the marginal effects of risk-taking and personality traits on criminality in column 8 in Table 4. For risk-taking $-(0.1 * 0.52)^{*} 0.012=0.062 \mathrm{ppts}$; for neuroticism $-\left(0.1^{*} 0.323\right)^{*} 0.019=0.062$ ppts. Note that although the prevailing sex ratio is associated with increased impatience, impatience has an insignificant effect on criminality.

${ }^{34}$ From Table 2 Column 3, the total effect of a ten percentage point increase in the sex ratio on criminality is 1.2 percentage points. $0.11 / 1.2=9.2 \%$.

${ }^{35} \mathrm{~A}$ comparison of the average monthly income prisoners reported from illegal activity and legal income reported by our non-inmate sample shows that illegal activities generated on average an extra RMB 252,000 (USD42,000) per year. With bride prices in China reported to be in the region of USD15,000, it appears that crime does pay sufficiently to be able to afford a bride. Further, the burden of finding the bride price (given its lump sum once-off nature) is likely to be bigger than that associated with maintaining a family. The average cost of raising a child was recently estimated to be USD3,622 per year in China, http://www.cnbc.com/2015/10/30/why-chinas-child-policy-doesnt-add-up-for-its-citizens.html.
} 
interact the prevailing sex ratio with whether the respondent is married or not. The existing literature, in particular, the social biology literature, predominantly relates individuals' behaviours to their own reproductive needs. However, in a society where the traditional family structure is still highly valued, individuals may take into account their offsprings' reproductive needs. The sex ratio may thus also exert a greater pressure upon men who have children (particularly sons who carry on the family name) than those who don't. ${ }^{36}$ To investigate this avenue, we also interact the prevailing sex ratio with a variable that indicates whether the respondent has children, and allow this to vary with the presence of sons (by interacting the sex ratio and a variable defined to equal one if the respondent only has daughters and is unlikely to have any more children, as indicated by the youngest child being more than 10 years of age, and zero otherwise). ${ }^{37}$

Table 5 reports the results. Column (1) shows that for unmarried men the prevailing sex ratio is strongly positively associated with the probability of being incarcerated. A 10 percentage point increase in the prevailing sex ratio is associated with a 1.8 percentage point increase in the probability of incarceration. This effect is largely offset for married men and becomes insignificant $(\mathrm{p}=0.38)$. Column (2) explores the effects of having children. It shows that men with children are slightly more likely to be in prison than men without children. This impact does not vary with the sex of the child.

In summary, sex ratios affect criminality a little through behavioural impacts but most of the impact operates via the direct impact on unmarried men through the marriage market.

\footnotetext{
${ }^{36}$ In modern China, although many middle income families have adopted western values, traditional Confucian teachings are still strong, particularly in rural areas. In Confucian thought, filial piety is considered the first virtue. In discussing filial piety one of the most renown Chinese philosophers, Mencius, finds that there are three ways of being unfilial, and to have no posterity (no descendants) is the greatest of them, Lee (2004), page 142. Thus, having male descendants to carry on the family name is of prime importance.

${ }^{37}$ Note that to the extent that divorce rates are high in prison, marital status may be endogenous. We do not have information on the date of divorces but note that the average length of time spent in prison in our prison sample is only 2.6 years and that divorce rates are low in our sample - only $7 \%$ of prisoners in our sample are divorced. Reporting having children could also be endogenous if divorced men are less likely to claim to have children. There is little evidence of this in our data though as $77 \%$ of divorced individuals report having children.
} 


\subsection{What Types of Crime?}

We now examine whether a high sex ratio is related to particular types of crime. The discussion above would suggest that it is related to economic crime, as unmarried men try to make themselves more financially attractive in the marriage market. The socio-biological and criminology literature however suggests that high sex ratios may result in greater aggression towards females, and so we might expect a greater increase in violent crime.

The prison administrative data provide detailed descriptions of crime types. We have coded them into two, not mutually exclusive, categories: violent crime (including robbery, sexual offences, and violence - accounting for $64 \%$ of crimes); and economic crime (including robbery, burglary, drug dealing, and other economic crime such as providing gambling venues, illegal business dealings, etc. - accounting for $70 \%$ of crimes). We also examine sexual crime separately so as to be able to examine whether the sex ratio has any association with sexual assault (accounting for only 4\% of crimes). We report marginal effects from logits on the prison sample with violent crime, sexual offences or economic crime as the dependent variable.

We find that economic crime is positively associated with the sex ratio and that again this relationship is being driven by unmarried men. The prevailing sex ratio is not associated with violent or sexual crimes (see Table 6).

\section{Conclusions}

To conclude, we find that sex ratios are positively associated with the propensity to commit crimes. Some of this relationship is accounted for by the finding that exposure to a high sex ratio early in life is associated with greater risk-taking and slightly greater neuroticism. This behavioural component is however relatively small, explaining $9 \%$ of the overall impact of the sex ratio. The direct pressure on men to find a partner in the marriage market is the primary driver of the increases in crime. Men turn to criminal activity in response to the greater competition in finding a mate and the need to appear more financially attractive. These marriage market pressures result in a higher propensity to commit financially rewarding 
crimes.

Recently, in response to the skewing of sex ratios, the rapid aging of the population, and reports of behavioural problems among the single child generation, the Chinese government relaxed the One Child Policy and now allows all couples to have two children. It remains unclear, however, to what extent this change will ultimately affect sex ratios, and hence what are the implications for crime. Some researchers have predicted little change in fertility behaviour (Cai, 2010). Even if the new policy does result in more balanced sex ratios, it will take at least a generation before the ratio between men and women in the marriage market approaches parity. Hence, the current marriage market pressures are likely to be sustained and possibly worsen in the short term, with the concomitant incentives to engage in crime.

Author Affiliations: Lisa Cameron - Melbourne Institute of Applied Economic and Social Research, University of Melbourne. Xin Meng - Research School of Economics, ANU College of Business and Economics, Australian National University. Dandan Zhang - National School of Development, Peking University. 


\section{References}

Baochang, G., Feng, W., Zhigang, G. and Erli, Z. (2007). 'China's local and national fertility policies at the end of the twentieth century', Population and Development Review, vol. 33(1), pp. 129-147.

Barber, N. (2003). 'The sex ratio and female marital opportunity as historical predictors of violent crime in england. scotland, and the united states', Cross-Cultural Research, vol. 37(4), pp. 373392.

BBC Trending (2016). 'The rising cost of a chinese bride price', http://www.bbc.com/news/ blogs-trending-35727057, [Online; accessed 10-June-2017].

Becker, G.S. (1968). 'Crime and punishment: An economic analysis', Journal of Political Economy, vol. 76(2), pp. 169-217.

Birkeland, S., Cappelen, A., Sorenson, E. and Tungodden, B. (2011). 'Immoral criminals? an experimental study of social preferences among prisoners', Norwegian School of Economics Working Paper, vol. SAM 122011.

Blair, P.S., Fleming, P.J., Bensley, D., Smith, I., Bacon, C., Taylor, E., Berry, J., Golding, J. and Tripp, J. (1996). 'Smoking and the sudden infant death syndrome: results from 1993-5 case-control study for confidential inquiry into stillbirths and deaths in infancy', British Medical Journal, vol. 313.

Cai, Y. (2010). 'China's below-replacement fertility: Government policy or socioeconomic development?', Population and Development Review, vol. 36(3), pp. 419-440.

Cameron, L., Chaudhuri, A., Erkal, N. and Gangadharan, L. (2009). 'Do attitudes towards corruption differ across cultures? experimental evidence from australia, india, indonesia and singapore', Journal of Public Economics, vol. 93, pp. 843-851.

Chen, Y., Li, H. and Meng, L. (2013). 'Prenatal sex seletion and missing girls in china: Evidence from the diffusion of diagnostic ultrasound', Journal of Human Resources, vol. 48(1), pp. 36-70.

Chuang, Y. and Schechter, L. (1996). 'Stability of social, risk, and time preferences over multiple years', Journal of Development Economics, vol. 117, pp. 151-170.

Costa, P.T. and Macrae, R.R. (1994). 'Set like plaster? evidence for the stability of adult personality', in (T. F. Heatherton and J. L. Weinberger, eds.), Can personality change?, pp. 21-40, Washington DC: American Psychological Association.

Dobrin, A. (2001). 'The risk of offending on homocide victimization: A case control study', Criminology and Penology, vol. 38(2), pp. 154-73.

Dreze, J. and Khera, R. (2000). 'Crime, gender, and society in india: Insights from homicide data', Population and Development Review, vol. 26(2).

Edlund, L., Li, H., Yi, J. and Zhang, J. (2007). 'Sex ratios and crime: Evidence from china', IZA Discussion Paper, (3214). 
Edlund, L., Li, H., Yi, J. and Zhang, J. (2013). 'Sex ratios and crime: Evidence from china', Review of Economics and Statistics, vol. 95(5), pp. 1520-1534.

Egan, V. (2009). 'The big five: Neuroticism, extroversion, openness, agreeableness and conscientiousness as an organisational scheme for thinking about aggression and violence', in (M. McMurran and R. Howard, eds.), Can personality change?, pp. 63-84, Chichester: Wiley and Sons, Ltd.

Friesen, L. (2012). 'Certainty of punishment versus severity of punishment: An experimental investigation', Southern Economic Journal, vol. 79(2), pp. 399-421.

Friesen, L. and Gangadharan, L. (2013). 'Designing self-reporting regimes to encourage truth telling: An experimental study', Journal of Economic Behavior and Organisation, vol. 94, pp. 90-102.

Gan, L., Zhcnao, Y., Nan, J., Shu, X., Shuang, M. and Lu, Z. (2013). Data you need to know about China: Research Report of China Household Finance Survey, New York: Springer.

Ganatra, B., Coyaji, K. and Rao, V. (1998). 'Too far, too little, too late: a community-based case-control study of maternal mortality in rural west maharashtra, india', Bulletin of the World Health Organisation, vol. 76(6), pp. 591-598.

Gneezy, U., Imas, A. and List, J. (2015). 'Estimating individual ambiguity aversion: A simple approach', NBER Working Paper, vol. 20982, pp. 1-23.

Gottfredson, M.R. and Hisrchi, T. (1990). A General Theory of Crime, Stanford: Stanford University Press.

Hu, L. (2006). Zhuan Xing Yu Fan Zui: Zhong Guo Zhuan Xing Qi Fan Zui Wen Ti De Shi Zheng Yan Jiu [Transition and Crime: An Empirical Analysis of Crime during Chinas Economic Transition], Beijing: Central Communist Party School Press.

Hudson, V. and Boer, A.M.D. (2002). 'A surplus of men, a deficit of peace: Security and sex ratios in asias largest states', International Security, vol. 26(4), pp. 5-38.

King, G. and Zeng, L. (2001). 'Logistic regression in rare events data', Political Analysis, vol. 9(2), pp. 137-163.

Le Galliard, J.F., Fitze, P.S., Ferriere, R. and Clobert, J. (2005). 'Sex ratio bias, male aggression, and population collapse in lizards', Proceedings of National Academy of Science, vol. 102(50), pp. 18231-18236.

Lee, C. (2004). 'Emperor chengzu and imperial filial piety of the min dynasty', in (A. Chan and S. Tan, eds.), Filial Piety in Chinese Thought and History, Routledge.

Liu, J. (2005). 'Crime patterns during the market transition in china', The British Journal of Criminology, vol. 45, pp. 613-633.

MacDonald, J.M., Haviland, A. and Morral, A.R. (2009). 'Assessing the relationship between violent and nonviolent criminal activity among serious adolescent offenders', Journal of Research in Crime and Delinquency, vol. 46(4), pp. 553-580. 
Mazar, N., Amir, O. and Ariely, D. (2008). 'The dishonesty of honest people: a theory of selfconcept maintenance', Journal of Marketing Research, vol. 45, pp. 633-644.

Michler, S., Nicolaus, M., Ubels, R., van der Velde, M., Botha, C. and ans Jan Komdeur, J.T. (2011). 'Do sex-specific densities affect local survival of free-ranging great tits', Behavioral Ecology, vol. 22, pp. 869-879.

Mu, Z. and Xie, Y. (2014). 'Marital age homogamy in china: A reversal of trend in the reform era?', Social Science Research, vol. 0, pp. 141-157.

Murnighan, J.K., Roth, A.E. and Schoumaker, F. (1988). 'Risk aversion in bargaining: An experimental study', Journal of Risk and Uncertainty, vol. 1(1), pp. 101-124.

NBS (2014). 2013 National Economic and Social Development Statistical Report, Beijing: China Statistics Press.

Solon, G., Haider, S.J. and Wooldridge, J.M. (2015). 'What are we weighting for?', Journal of Human Resources, vol. 50(2), pp. 301-316.

South China Morning Post (2016). '100,000 yuan and counting? the price china's rural bachelars must pay to get a wife', http://www.scmp.com/news/china/society/article/2072313/ cost-bridegroom-gifts-secure-permission-marry-soars-china, [Online; accessed 10June-2017].

South China Morning Post (2017). 'How much does it cost a man to get married in china? clue: it involves a flat and wads of cash', http://www.scmp.com/news/china/society/article/ 1916758/100000-yuan-and-counting-price-chinas-rural-bachelors-must-pay, [Online; accessed 10-June-2017].

Wei, S.J. and Zhang, Z. (2011). 'The competitivs saving motive: Evidence from rising sex ratios and savings rates in china', Journal of Political Economy, vol. 119(3), pp. 511-564.

Wiebe, R.P. (2004). 'Delinquent behavior and the five-factor model: Hiding in the adaptive landscape?', Individual Differences Research, vol. 2(1), pp. 38-52.

Wilson, M. and Daly, M. (1985). 'Competitiveness, risk taking and violence: The young male syndrome', Ethology and Sociobiology, vol. 6, pp. 59-73.

Wright, R. (1994). The Moral Animal. Why We Are the Way We Are. The New Science of Evolutionary Psychology, New York: Vintage.

Xie, Y. and Manski, C.F. (2010). 'The logit model, the probit model, and response-based samples', University of Wisconsin-Madison, Center for Demography and Ecology, vol. 88-4.

Zhang, J. (2011). 'Research into six important relationships which affect significant increase in chinas crime rate', Chinese University of Public Security Report (in Chinese), vol. 5.

Zhang, Y., Liu, S.Q. and Liu, L. (2011). 'Rural-urban income difference, unemployment of migrants, and increase in chinas crime rate', Economic Research (In Chinese).

Zhu, Xing, W., Lu, L. and Hesketh, T. (2009). 'Chinas excess males, sex selective abortion, and one child policy: Analysis of data from 2005 national intercensus survey', British Medical Journal, vol. 338 . 
Table 1: Summary Statistics

\begin{tabular}{|c|c|c|c|c|}
\hline Variable & $\begin{array}{c}\text { Mean } \\
\text { All }\end{array}$ & $\begin{array}{c}\text { Mean } \\
\text { Inmates }\end{array}$ & $\begin{array}{c}\text { Mean } \\
\text { Migrants }\end{array}$ & Difference \\
\hline \multicolumn{5}{|l|}{ Individual Variables: } \\
\hline Age & 29.70 & 29.85 & 29.32 & 0.54 \\
\hline Years of schooling & 8.84 & 7.86 & 11.22 & $-3.36^{* * *}$ \\
\hline IQ test score & 6.23 & 5.93 & 6.95 & $-1.02 * * *$ \\
\hline Married & 0.35 & 0.32 & 0.43 & $-0.10^{* * *}$ \\
\hline Number of children & 0.66 & 0.69 & 0.57 & $0.12^{* *}$ \\
\hline Father's years of schooling & 7.15 & 6.78 & 8.03 & $-1.25^{* * *}$ \\
\hline Mother's years of schooling & 5.39 & 4.82 & 6.78 & $-1.96^{* * *}$ \\
\hline \multicolumn{5}{|l|}{ Prefecture Variables: } \\
\hline Log of per capita GDP & 9.40 & 9.37 & 9.47 & $0.09 * * *$ \\
\hline Gini coefficient & 0.35 & 0.35 & 0.35 & $-0.01 *$ \\
\hline Out-migration rate & 2.05 & 1.85 & 2.53 & $0.68^{* * *}$ \\
\hline Minority population share & 0.10 & 0.12 & 0.04 & $-0.08^{* * *}$ \\
\hline \multicolumn{5}{|l|}{ Behavioural Variables: } \\
\hline Patience & 5.32 & 5.26 & 5.46 & -0.20 \\
\hline Least Patient & 0.29 & 0.31 & 0.22 & $0.09 * * *$ \\
\hline Risk Loving & 6.43 & 6.17 & 7.06 & $0.90 * * *$ \\
\hline Riskiest & 0.21 & 0.24 & 0.13 & $0.10^{* * *}$ \\
\hline \multicolumn{5}{|l|}{ Big 5 Personality Traits: } \\
\hline Neuroticism & 3.07 & 3.10 & 2.99 & $0.11^{* * *}$ \\
\hline Openness & 3.25 & 3.19 & 3.42 & $-0.23 * * *$ \\
\hline Agreeableness & 3.05 & 3.03 & 3.09 & $-0.06 * * *$ \\
\hline Extroversion & 3.17 & 3.12 & 3.26 & $-0.14^{* * *}$ \\
\hline Conscientiousness & 3.20 & 3.16 & 3.28 & $-0.11^{* * *}$ \\
\hline \multicolumn{5}{|l|}{ Sex Ratios: } \\
\hline Prevailing sex ratio & 1.14 & 1.15 & 1.12 & $0.03 * * *$ \\
\hline Own cohort sex ratio & 1.13 & 1.13 & 1.11 & $0.03 * * *$ \\
\hline $\mathrm{N}$ & 1006 & 712 & 294 & \\
\hline
\end{tabular}

Notes: $* * *$ indicates significance at $1 \%$ level, ${ }^{* *}$ at $5 \%$ level, ${ }^{*}$ at $10 \%$ level. 
Table 2: Is the Sex Ratio a Determinant of Criminal Activity?

\begin{tabular}{|c|c|c|c|c|c|c|}
\hline & \multicolumn{6}{|c|}{ Dependent Variable $=$ Prisoner $(0 / 1)$} \\
\hline & \multicolumn{2}{|c|}{ (1) } & \multicolumn{2}{|c|}{$(2)$} & \multicolumn{2}{|c|}{ (3) } \\
\hline & coeffs & $\begin{array}{c}\text { marginal } \\
\text { effects }\end{array}$ & coeffs & $\begin{array}{c}\text { marginal } \\
\text { effects }\end{array}$ & coeffs & $\begin{array}{c}\text { marginal } \\
\text { effects }\end{array}$ \\
\hline \multicolumn{7}{|l|}{ A: Prevailing sex ratio } \\
\hline Prevailing sex ratio & $\begin{array}{c}6.273^{* * *} \\
{[2249]}\end{array}$ & $\begin{array}{c}0.029^{* * *} \\
{[0.011]}\end{array}$ & $\begin{array}{c}6.131^{* *} \\
{[2.989]}\end{array}$ & $\begin{array}{c}0.082^{* *} \\
{[0.039]}\end{array}$ & $\begin{array}{c}8.422 * * \\
{[3358]}\end{array}$ & $\begin{array}{c}0.120^{* *} \\
{[0.051]}\end{array}$ \\
\hline \multirow[t]{2}{*}{ Age } & & & 0.003 & 0.000 & 0.001 & 0.000 \\
\hline & & & [0.018] & {$[0.000]$} & {$[0.018]$} & {$[0.000]$} \\
\hline \multirow[t]{2}{*}{ Years of schooling } & & & $-0.502^{* * *}$ & $-0.007^{* * *}$ & $-0.507 * * *$ & $-0.007^{* * *}$ \\
\hline & & & {$[0.054]$} & [0.002] & [0.053] & [0.002] \\
\hline \multirow[t]{2}{*}{ IQ test score } & & & 0.011 & 0.000 & 0.020 & 0.000 \\
\hline & & & {$[0.036]$} & {$[0.000]$} & {$[0.035]$} & {$[0.001]$} \\
\hline \multirow[t]{2}{*}{ Married } & & & $-1.244^{* * *}$ & $-0.017^{* * *}$ & $-1.326 * * *$ & $-0.019 * * *$ \\
\hline & & & [0.276] & [0.006] & [0.284] & [0.006] \\
\hline \multirow[t]{2}{*}{ Number of children } & & & $0.496^{* * *}$ & $0.007^{* *}$ & $0.598 * * *$ & $0.009 * * *$ \\
\hline & & & {$[0.177]$} & {$[0.003]$} & {$[0.181]$} & {$[0.003]$} \\
\hline \multirow[t]{2}{*}{ Father's years of schooling } & & & -0.005 & 0.000 & -0.006 & 0.000 \\
\hline & & & {$[0.025]$} & {$[0.000]$} & {$[0.026]$} & {$[0.000]$} \\
\hline \multirow[t]{2}{*}{ Mother's years of schooling } & & & $-0.065^{* *}$ & $-0.001^{* *}$ & $-0.067 * *$ & $-0.001^{* *}$ \\
\hline & & & [0.029] & {$[0.000]$} & {$[0.030]$} & {$[0.000]$} \\
\hline \multirow{2}{*}{ Log of prefecture GDP } & & & & & 0.464 & 0.007 \\
\hline & & & & & {$[0.419]$} & {$[0.006]$} \\
\hline \multirow[t]{2}{*}{ Gini coefficient for the Pref. } & & & & & 3.014 & 0.043 \\
\hline & & & & & {$[2.976]$} & {$[0.045]$} \\
\hline \multirow[t]{2}{*}{ Out-migration rate } & & & & & -0.032 & 0.000 \\
\hline & & & & & {$[0.028]$} & {$[0.000]$} \\
\hline \multirow{2}{*}{ Minority population share } & & & & & $3.209 * * *$ & $0.046^{* * *}$ \\
\hline & & & & & {$[0.926]$} & {$[0.015]$} \\
\hline Pseudo R-Squared & \multicolumn{2}{|c|}{0.05} & \multicolumn{2}{|c|}{0.29} & \multicolumn{2}{|c|}{0.32} \\
\hline $\mathrm{N}$ & \multicolumn{2}{|c|}{1006} & \multicolumn{2}{|c|}{1006} & & \\
\hline B: Own cohort sex ratio & & & & & & \\
\hline Own cohort sex ratio & $1.926^{* *}$ & $0.009 * *$ & $2.666^{* *}$ & $0.035^{* *}$ & $2.825^{* *}$ & $0.039^{* *}$ \\
\hline & {$[0.960]$} & {$[0.004]$} & {$[1.257]$} & {$[0.016]$} & {$[1.270]$} & {$[0.018]$} \\
\hline Controls & & & & & & \\
\hline Pseudo R-Squared & & & & & & \\
\hline $\mathrm{N}$ & & & & & & \\
\hline C: Instrumental Variables Res & ts - Pre & iling sex & atio & & & \\
\hline Prevailing sex ratio & $16.434^{* *}$ & $0.079 * *$ & $17.349^{*}$ & $0.236^{*}$ & $16.158^{*}$ & $0.225^{*}$ \\
\hline & {$[6.747]$} & {$[0.036]$} & {$[8.221]$} & {$[0.115]$} & {$[7.856]$} & {$[0.118]$} \\
\hline Controls & & & & & & \\
\hline F-test for 1st Stage Strength of IV & & & & & & \\
\hline $\mathrm{N}$ & & & & & & \\
\hline D:Instrumental Variables Resu & $\mathbf{s}-$ Own & Cohort se & ratio & & & \\
\hline Own Cohort sex ratio & $14.555^{* *}$ & $0.070^{* *}$ & $15.235^{* *}$ & $0.207^{*}$ & $14.776^{* *}$ & $0.206^{*}$ \\
\hline & {$[6.000]$} & {$[0.032]$} & {$[7.529]$} & {$[0.105]$} & {$[7.434]$} & {$[0.111]$} \\
\hline Controls & & & & & & \\
\hline F-test for 1st Stage Strength of IV & & & & & & \\
\hline $\mathrm{N}$ & & & & & & \\
\hline
\end{tabular}

Notes: We report coefficients and marginal effects from logistic regressions. The calculation of the marginal effects is corrected for choice-based sampling using the method of prior correction, see King and Zeng (2001). The IV estimations use as instruments an interaction between the inverse of the ethnic minority share and a variable reflecting the severity of the implementation of the policy; and an interaction between the inverse of the ethnic minority share and the number of years prior to 2013 that an ultrasound B-scan machine was installed in the county. The IV standard errors are bootstrapped using 2000 repetition. All specifications include provincial fixed effects. Standard errors are clustered by prefecture. All specifications in Columns (2) and (3) include the controls shown in Panel A. ${ }^{* * *}$ indicates significance at $1 \%$ level, ${ }^{* *}$ at $5 \%$ level, ${ }^{*}$ at $10 \%$ level. 


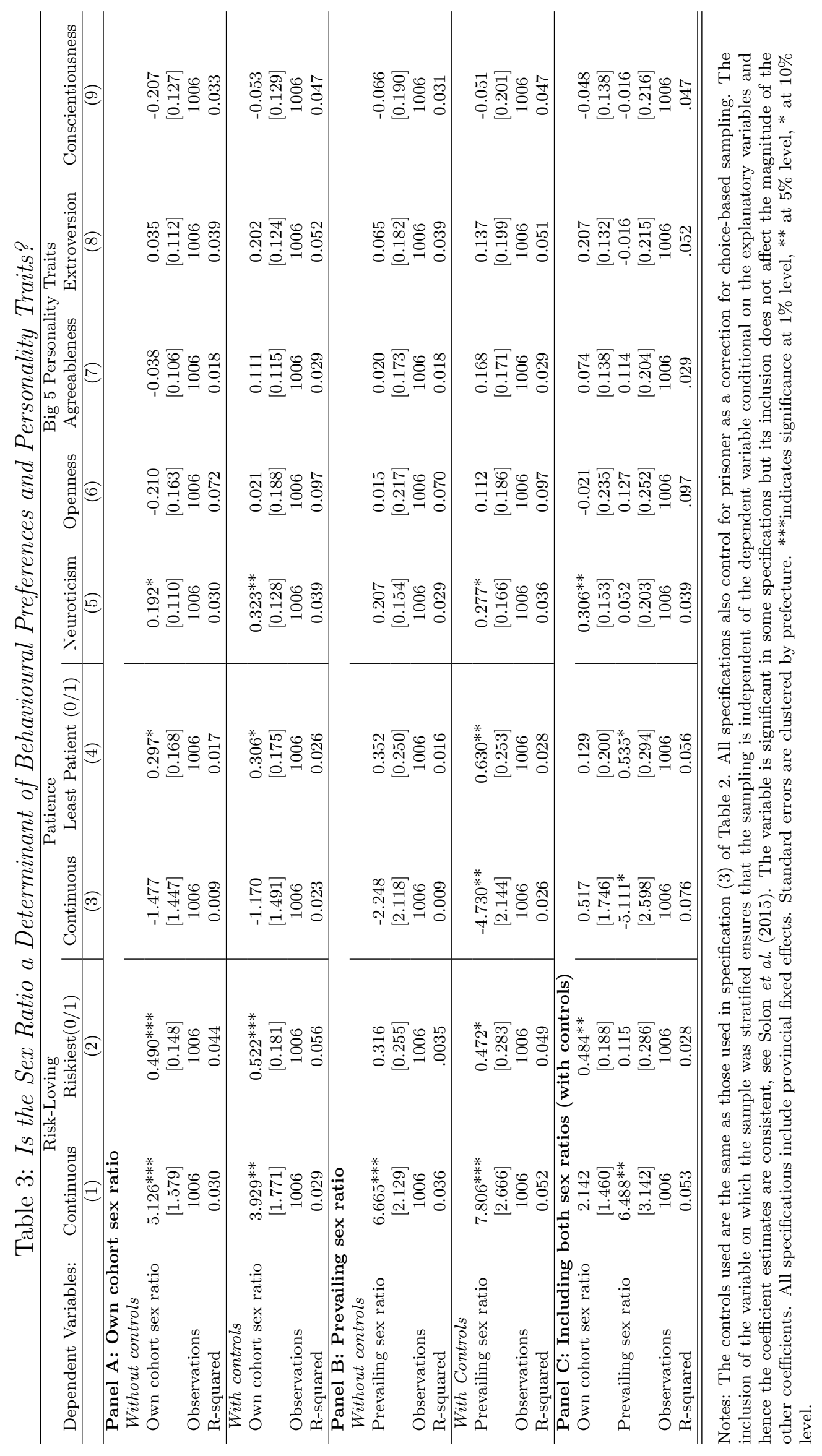


Table 4: Are Behavioural Preference and Personality Traits Determinants of Criminality?

Panel A: Dependent Variable: Prisoner=1, with no controls

\begin{tabular}{|c|c|c|c|c|c|c|c|c|}
\hline & \multicolumn{2}{|c|}{ Without Sex Ratio } & \multicolumn{3}{|c|}{ Own Cohort Sex Ratio } & \multicolumn{3}{|c|}{ Prevailing Sex Ratio } \\
\hline & $(1)$ & $(2)$ & $(3)$ & $(4)$ & $(5)$ & $(6)$ & $(7)$ & $(8)$ \\
\hline Own cohort Sex Ratio & & & $\begin{array}{c}0.009^{* *} \\
{[0.004]}\end{array}$ & $\begin{array}{c}0.007 \\
{[0.005]}\end{array}$ & $\begin{array}{c}0.006 \\
{[0.006]}\end{array}$ & & & \\
\hline Prevailing sex ratio & & & & & & $\begin{array}{c}0.029 * * * \\
{[0.011]}\end{array}$ & $\begin{array}{c}0.029 * * * \\
{[0.011]}\end{array}$ & $\begin{array}{c}0.037^{* *} \\
{[0.014]}\end{array}$ \\
\hline Riskiest & $\begin{array}{c}0.003^{* * *} \\
{[0.001]}\end{array}$ & $\begin{array}{c}0.004^{* * *} \\
{[0.001]}\end{array}$ & & $\begin{array}{c}0.003^{* * *} \\
{[0.001]}\end{array}$ & $\begin{array}{c}0.004^{* * *} \\
{[0.001]}\end{array}$ & & $\begin{array}{c}0.003^{* * *} \\
{[0.001]}\end{array}$ & $\begin{array}{c}0.004^{* * *} \\
{[0.002]}\end{array}$ \\
\hline Least-Patient & $\begin{array}{c}0.002^{* *} \\
{[0.001]}\end{array}$ & $\begin{array}{l}0.002^{*} \\
{[0.001]}\end{array}$ & & $\begin{array}{c}0.002^{* *} \\
{[0.001]}\end{array}$ & $\begin{array}{l}0.002^{*} \\
{[0.001]}\end{array}$ & & $\begin{array}{c}0.002^{* *} \\
{[0.001]}\end{array}$ & $\begin{array}{c}0.002 \\
{[0.001]}\end{array}$ \\
\hline Neuroticism & & $\begin{array}{c}0.007^{* * *} * \\
{[0.002]}\end{array}$ & & & $\begin{array}{c}0.007^{* * *} \\
{[0.002]}\end{array}$ & & & $\begin{array}{c}0.007^{* * *} * \\
{[0.002]}\end{array}$ \\
\hline Openness & & $\begin{array}{c}-0.007^{* * *} \\
{[0.002]}\end{array}$ & & & $\begin{array}{c}-0.007 * * * \\
{[0.002]}\end{array}$ & & & $\begin{array}{c}-0.007^{* * *} \\
{[0.002]}\end{array}$ \\
\hline Agreeableness & & $\begin{array}{c}0.001 \\
{[0.002]}\end{array}$ & & & $\begin{array}{c}0.001 \\
{[0.002]}\end{array}$ & & & $\begin{array}{c}0.001 \\
{[0.002]}\end{array}$ \\
\hline Extroversion & & $\begin{array}{c}-0.004^{* *} \\
{[0.001]}\end{array}$ & & & $\begin{array}{c}-0.004^{* *} \\
{[0.001]}\end{array}$ & & & $\begin{array}{c}-0.004^{* *} \\
{[0.002]}\end{array}$ \\
\hline Conscientiousness & & $\begin{array}{c}-0.005^{* *} \\
{[0.002]}\end{array}$ & & & $\begin{array}{c}-0.004^{* *} \\
{[0.002]}\end{array}$ & & & $\begin{array}{c}-0.005^{* *} \\
{[0.002]}\end{array}$ \\
\hline Controls & No & No & No & No & No & No & No & No \\
\hline Observations & 1006 & 1006 & 1006 & 1006 & 1006 & 1006 & 1006 & 1006 \\
\hline Pseudo R-Squared & 0.050 & 0.141 & 0.041 & 0.056 & 0.142 & 0.051 & 0.063 & 0.152 \\
\hline
\end{tabular}

Panel B: Dependent Variable: Prisoner=1, with full controls

\begin{tabular}{|c|c|c|c|c|c|c|c|c|}
\hline \multirow{2}{*}{ Own cohort sex ratio } & \multicolumn{2}{|c|}{ Without Sex Ratio } & \multicolumn{3}{|c|}{ Own Cohort Sex Ratio } & \multicolumn{3}{|c|}{ Prevailing Sex Ratio } \\
\hline & & & $\begin{array}{c}0.039^{* *} \\
{[0.018}\end{array}$ & $\begin{array}{l}0.034^{*} \\
{[0.019]}\end{array}$ & $\begin{array}{c}0.035 \\
{[0.023]}\end{array}$ & & & \\
\hline Prevailing sex ratio & & & & & & $\begin{array}{c}0.120^{* *} \\
{[0.051]}\end{array}$ & $\begin{array}{c}0.122^{* *} \\
{[0.052]}\end{array}$ & $\begin{array}{c}0.134^{* *} \\
{[0.062]}\end{array}$ \\
\hline Riskiest & $\begin{array}{c}0.010^{* * *} \\
{[0.004]}\end{array}$ & $\begin{array}{c}0.011^{* * *} \\
{[0.004]}\end{array}$ & & $\begin{array}{c}0.010^{* *} \\
{[0.004]}\end{array}$ & $\begin{array}{c}0.011^{* *} \\
{[0.004]}\end{array}$ & & $\begin{array}{c}0.010^{* * *} \\
{[0.004]}\end{array}$ & $\begin{array}{c}0.012^{* * *} \\
{[0.004]}\end{array}$ \\
\hline Least-Patient & $\begin{array}{c}0.005 \\
{[0.003]}\end{array}$ & $\begin{array}{c}0.005 \\
{[0.004]}\end{array}$ & & $\begin{array}{c}0.004 \\
{[0.003]}\end{array}$ & $\begin{array}{c}0.004 \\
{[0.004]}\end{array}$ & & $\begin{array}{c}0.004 \\
{[0.003]}\end{array}$ & $\begin{array}{c}0.004 \\
{[0.004]}\end{array}$ \\
\hline Neuroticism & & $\begin{array}{c}0.018^{* * *} \\
{[0.005]}\end{array}$ & & & $\begin{array}{c}0.018^{* * *} \\
{[0.005]}\end{array}$ & & & $\begin{array}{c}0.019 * * * \\
{[0.005]}\end{array}$ \\
\hline Openness & & $\begin{array}{c}-0.012^{* *} \\
{[0.005]}\end{array}$ & & & $\begin{array}{c}-0.012^{* *} \\
{[0.005]}\end{array}$ & & & $\begin{array}{c}-0.013 * * * \\
{[0.005]}\end{array}$ \\
\hline Agreeableness & & $\begin{array}{c}0.004 \\
{[0.006]}\end{array}$ & & & $\begin{array}{c}0.004 \\
{[0.006]}\end{array}$ & & & $\begin{array}{c}0.003 \\
{[0.006]}\end{array}$ \\
\hline Extroversion & & $\begin{array}{c}-0.012^{* * *} \\
{[0.004]}\end{array}$ & & & $\begin{array}{c}-0.013 * * * \\
{[0.004]}\end{array}$ & & & $\begin{array}{c}-0.012^{* * *} * \\
{[0.004]}\end{array}$ \\
\hline Conscientiousness & & $\begin{array}{c}-0.015 * * * \\
{[0.005]}\end{array}$ & & & $\begin{array}{c}-0.015^{* * * *} \\
{[0.005]}\end{array}$ & & & $\begin{array}{c}-0.015^{* * *} \\
{[0.005]}\end{array}$ \\
\hline Controls & Yes & $\overline{\text { Yes }}$ & Yes & Yes & Yes & Yes & Yes & Yes \\
\hline Observations & 1006 & 1006 & 1006 & 1006 & 1006 & 1006 & 1006 & 1006 \\
\hline Pseudo R-Squared & 0.316 & 0.367 & 0.308 & 0.319 & 0.370 & 0.318 & 0.329 & 0.380 \\
\hline
\end{tabular}

Notes: We report marginal effects from logistic regressions. The calculation of the marginal effects is corrected for choice-based sampling using the method of prior correction, see King and Zeng (2001). The controls used in Panel B are those used in the full control specification in Table 2. All specifications include provincial fixed effects. Standard errors are clustered by prefecture. $* * *$ indicates significance at $1 \%$ level, $* *$ at $5 \%$ level, $*$ at $10 \%$ level. 
Table 5: Mechanisms via which the Sex Ratio Affects Criminality

Dependent Variable $=$ Prisoner $(0 / 1)$

\begin{tabular}{|c|c|c|c|c|}
\hline & \multicolumn{2}{|r|}{ (1) } & \multicolumn{2}{|r|}{$(2)$} \\
\hline & Coefficient & Marginal effect & Coefficient & Marginal effect \\
\hline \multirow[t]{2}{*}{ Prevailing sex ratio } & $11.160^{* * *}$ & $0.184^{* * *}$ & $11.321^{* * *}$ & $0.189^{* * *}$ \\
\hline & {$[3.570]$} & {$[0.065]$} & [3.633] & {$[0.066]$} \\
\hline \multirow[t]{2}{*}{ Married * Prevailing sex ratio } & $-7.046^{* *}$ & $-0.116^{* *}$ & $-7.618^{* *}$ & $-0.127^{* *}$ \\
\hline & {$[3.573]$} & {$[0.059]$} & [3.687] & {$[0.061]$} \\
\hline \multirow[t]{2}{*}{ Chidren * Prevailing sex ratio } & & & $0.886^{* *}$ & $0.015^{* *}$ \\
\hline & & & {$[0.418]$} & {$[0.007]$} \\
\hline \multirow[t]{2}{*}{ Only Daughters * Prevailing sex ratio } & & & -0.265 & -0.004 \\
\hline & & & {$[0.545]$} & {$[0.009]$} \\
\hline Standard Controls & \multicolumn{2}{|r|}{ Yes } & \multicolumn{2}{|r|}{ Yes } \\
\hline Behaviour Controls & \multicolumn{2}{|r|}{ Yes } & \multicolumn{2}{|r|}{ Yes } \\
\hline Big Five Controls & \multicolumn{2}{|r|}{ Yes } & \multicolumn{2}{|r|}{ Yes } \\
\hline Provincial Fixed Effects & \multicolumn{2}{|r|}{ Yes } & \multicolumn{2}{|r|}{ Yes } \\
\hline Observations & \multicolumn{2}{|r|}{1006} & \multicolumn{2}{|c|}{1006} \\
\hline Pseudo R-Squared & \multicolumn{2}{|c|}{0.379} & \multicolumn{2}{|c|}{0.384} \\
\hline
\end{tabular}

Notes: We report coefficients and marginal effects from logistic regressions. The calculation of the marginal effects is corrected for choice-based sampling using the method of prior correction, see King and Zeng (2001). The controls used are those used in Table 3 and controls for risk and time preferences and Big 5 personality traits. All specifications include provincial fixed effects. Standard errors are clustered by prefecture. ${ }^{* * *}$ indicates significance at $1 \%$ level, ${ }^{* *}$ at $5 \%$ level, ${ }^{*}$ at $10 \%$ level.

Table 6: What Type of Crime is Driven by the Sex Ratio?

\begin{tabular}{lcccc}
\hline & Violent Crime & Sexual Offence & Economic Crime & Economic Crime \\
\hline Prevailing sex ratio & -0.293 & 0.037 & $0.723^{*}$ & \\
Single*Prevailing sex ratio & {$[0.444]$} & {$[0.077]$} & {$[0.427]$} & $1.129^{* * *}$ \\
& & & & {$[0.399]$} \\
Married*Prevailing sex ratio & & & & 0.040 \\
& & & & {$[0.669]$} \\
\hline Standard Controls & Yes & Yes & Yes & Yes \\
Behaviour Controls & Yes & Yes & Yes & Yes \\
Big Five Controls & Yes & Yes & Yes & Yes \\
Provincial Fixed Effects & Yes & Yes & Yes & Yes \\
City of Arrest & Yes & Yes & Yes & Yes \\
Dummy for single Offence & Yes & Yes & Yes & Yes \\
N & 708 & 708 & 708 & 708 \\
Pseudo R-squared & 0.149 & 0.136 & 0.058 & 0.062 \\
\hline
\end{tabular}

Notes: We report marginal effects from logistic regressions. The sample is restricted to only those who are prisoners. The controls used are those used in Table 3 and controls for risk and time preferences and Big 5 personality traits. All specifications include provincial fixed effects. Standard errors are clustered by prefecture. ***indicates significance at $1 \%$ level, $* *$ at $5 \%$ level, * at $10 \%$ level. 


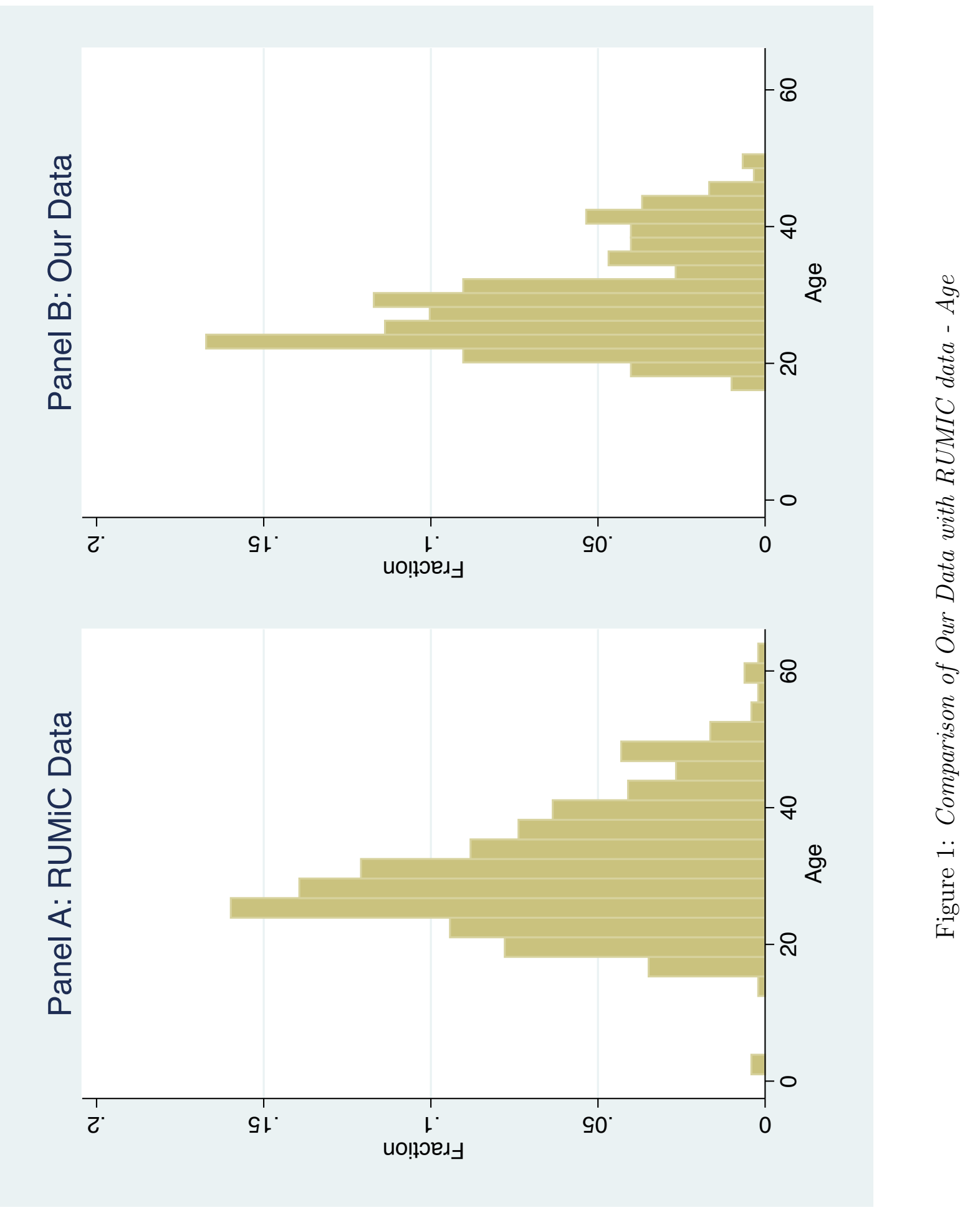




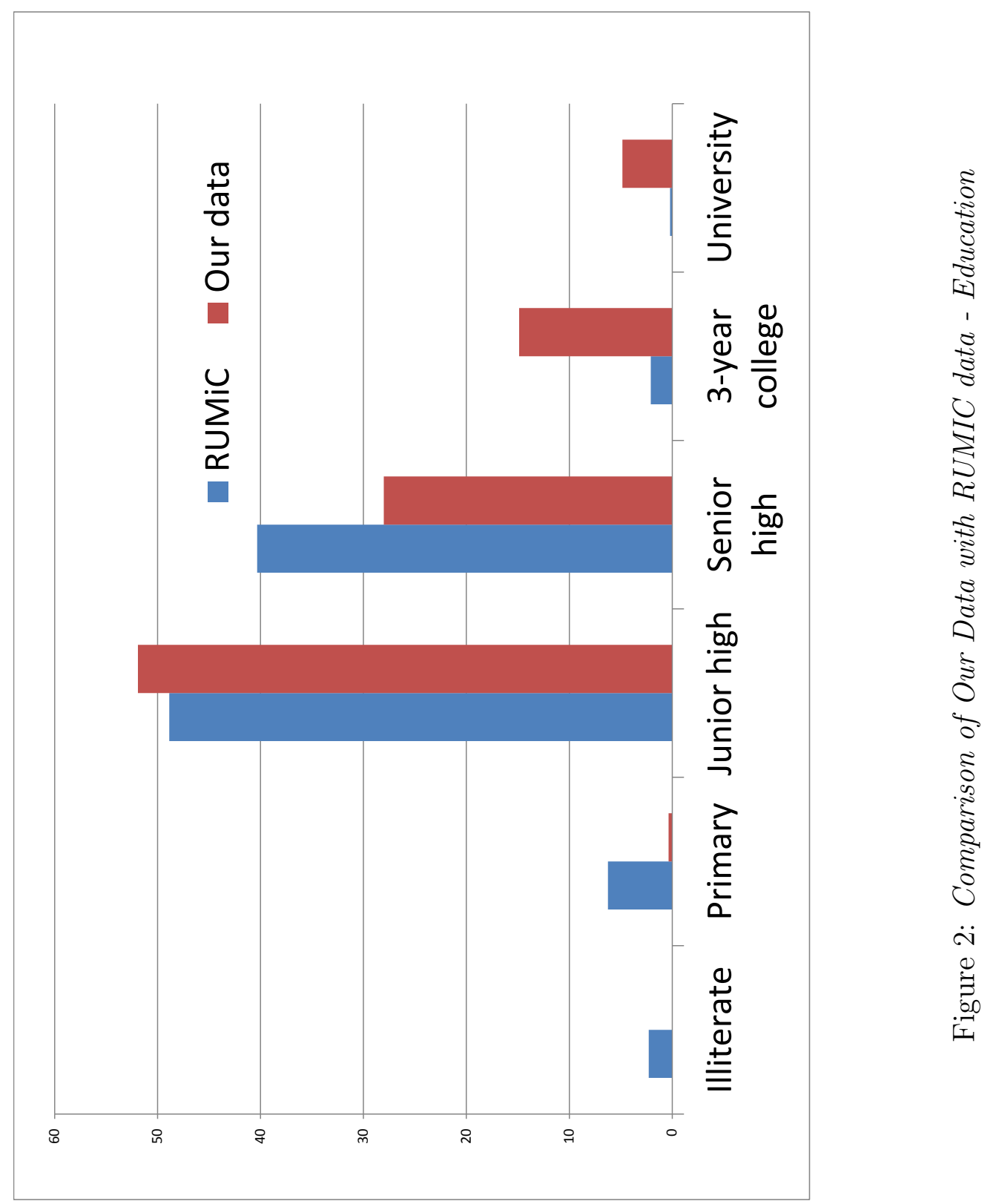




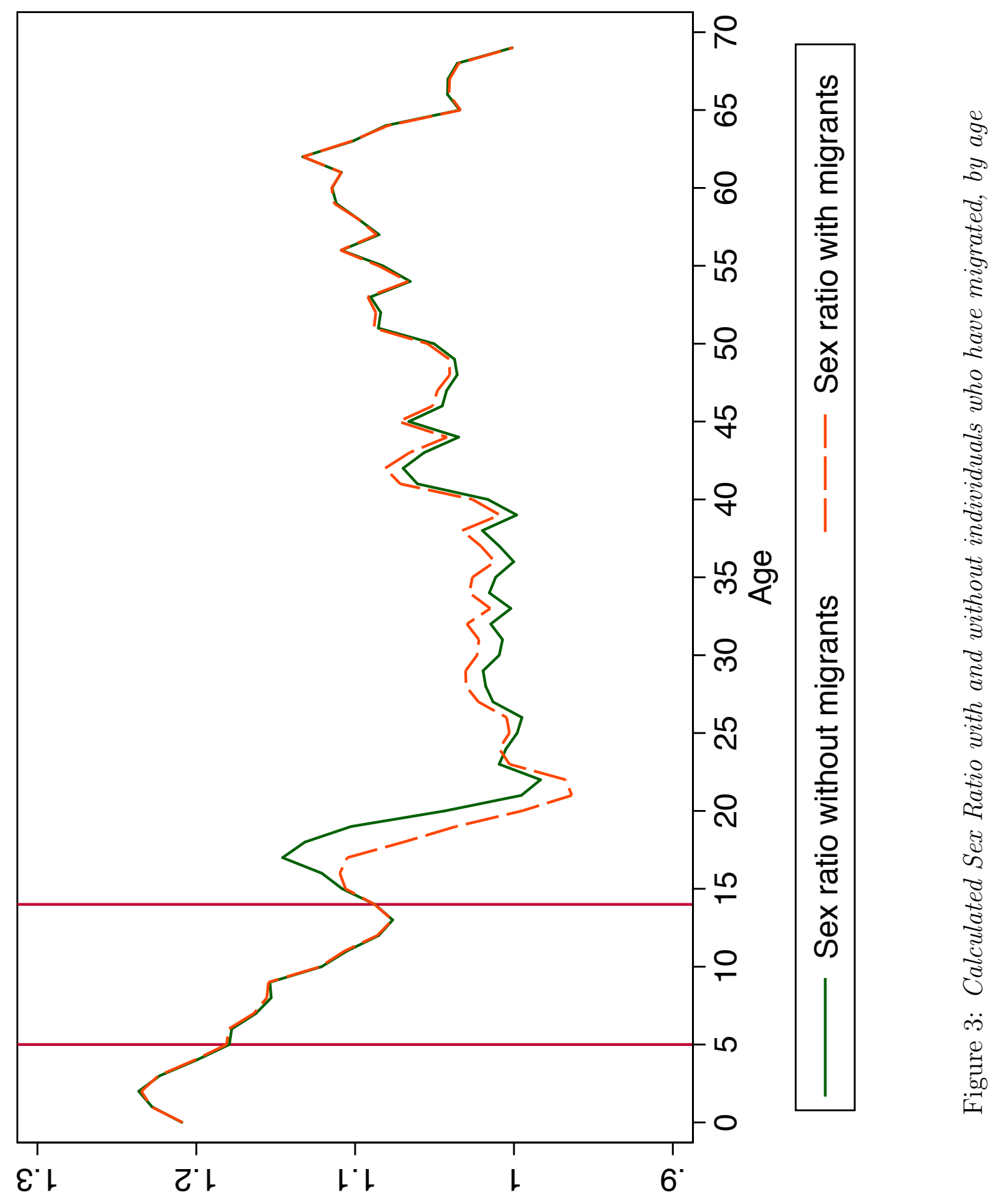




\section{A Appendix Tables}

\section{A.1 Calculation of Migrant and Prison Populations}

From the Social and Economic Development Statistical Report we know that in 2012 there were 767,130,000 migrant residents of Shenzhen (with non-local hukou). If we assume that about $90 \%$ of these are rural-urban migrants and about half are male, then we have an estimate of 3.45 million rural-urban male migrants in Shenzhen.

The same data source tells us that there were 50,315 arrests made in Shenzhen in 2012 and 2013. Using the prison administration data we calculate a prison inflow ratio (= inflow in 2012/2013 divided by the total number of prisoners in this period) of 0.55 . By dividing the total number of arrests in Shenzhen in $2012 / 2013$ by this inflow rate we obtain an estimate of the rural-urban migrant prison population in the city $=50,315 / 0.55=91,481$. The China Statistical Yearbook (2004-2013) tells us that in $201294.17 \%$ of prisoners are male. So our estimate of the male prison population is 86,148 . 
Table A1: Weighted versus Unweighted Logistic Regressions

\begin{tabular}{lcccc}
\hline \hline \multirow{4}{*}{ Dependent Variable: } & Prisoner $(0 / 1)$ & \multicolumn{2}{c}{ Weighted } \\
\hline & Coeffs & m.e.s & Coeffs & m.e.s \\
\hline Prevailing sex ratio & $8.155^{* *}$ & $0.122^{* *}$ & $5.796^{*}$ & $0.105^{*}$ \\
& {$[3.299]$} & {$[0.052]$} & {$[3.259]$} & {$[0.064]$} \\
Age & 0.003 & 0.000 & -0.018 & 0.000 \\
& {$[0.017]$} & {$[0.000]$} & {$[0.025]$} & {$[0.000]$} \\
Years of schooling & $-0.516^{* * *}$ & $-0.008^{* * *}$ & $-1.021^{* * *}$ & $-0.019^{* * *}$ \\
& {$[0.055]$} & {$[0.002]$} & {$[0.114]$} & {$[0.003]$} \\
IQ test score & 0.027 & 0.000 & -0.053 & -0.001 \\
& {$[0.036]$} & {$[0.001]$} & {$[0.043]$} & {$[0.001]$} \\
Married & $-1.338^{* * *}$ & $-0.020^{* * *}$ & $-1.338^{* * *}$ & $-0.024^{* * *}$ \\
& {$[0.289]$} & {$[0.006]$} & {$[0.386]$} & {$[0.008]$} \\
Number of children & $0.602^{* * *}$ & $0.009^{* * *}$ & $0.451^{* *}$ & $0.008^{* *}$ \\
& {$[0.184]$} & {$[0.003]$} & {$[0.205]$} & {$[0.004]$} \\
Father's years of schooling & -0.001 & 0.000 & 0.049 & 0.001 \\
& {$[0.025]$} & {$[0.000]$} & {$[0.043]$} & {$[0.001]$} \\
Mother's years of schooling & $-0.070^{* *}$ & $-0.001^{* *}$ & $-0.112^{* * *}$ & $-0.002^{* *}$ \\
& {$[0.029]$} & {$[0.000]$} & {$[0.042]$} & {$[0.001]$} \\
Log of Prefecture GDP & 0.429 & 0.006 & 0.126 & 0.002 \\
& {$[0.418]$} & {$[0.006]$} & {$[0.700]$} & {$[0.013]$} \\
Gini coefficient for the Pref. & 3.102 & 0.046 & 4.559 & 0.083 \\
& {$[2.885]$} & {$[0.046]$} & {$[5.734]$} & {$[0.102]$} \\
Out-migration rate & -0.029 & 0.000 & -0.011 & 0.000 \\
& {$[0.028]$} & {$[0.000]$} & {$[0.051]$} & {$[0.001]$} \\
Minority population share & $3.186^{* * *}$ & $0.047^{* * *}$ & $4.078^{* * *}$ & $0.074^{* * *}$ \\
& {$[0.930]$} & {$[0.016]$} & {$[1.089]$} & {$[0.023]$} \\
Riskiest & $0.703^{* * *}$ & $0.010^{* * *}$ & $1.043^{* * *}$ & $0.019^{* * *}$ \\
Least patient & {$[0.260]$} & {$[0.004]$} & {$[0.308]$} & {$[0.006]$} \\
& 0.275 & 0.004 & 0.375 & 0.007 \\
N & {$[0.223]$} & {$[0.003]$} & {$[0.310]$} & {$[0.005]$} \\
\hline \hline
\end{tabular}

Notes: The calculation of the marginal effects in the unweighted regressions is corrected for choice-based sampling using the method of prior correction. See King and Zeng (2001). ${ }^{* * *}$ indicates significance at $1 \%$ level, ${ }^{* *}$ at $5 \%$ level, ${ }^{*}$ at $10 \%$ level. 
Table A2: Sensitivity to Length of Time in Prison

\begin{tabular}{|c|c|c|c|c|}
\hline & \multicolumn{2}{|c|}{ Risk-Loving } & \multicolumn{2}{|c|}{ Patience } \\
\hline & Continuous & Riskiest & Continuous & Least Patient \\
\hline \multicolumn{5}{|l|}{ Panel A: Without Controls } \\
\hline \multirow[t]{2}{*}{ Prevailing Sex Ratio } & $6.368^{* * *}$ & 0.311 & -2.228 & 0.350 \\
\hline & {$[2.076]$} & {$[0.252]$} & {$[2.150]$} & {$[0.252]$} \\
\hline \multirow[t]{2}{*}{ Time spent in prison } & -0.015 & -0.003 & 0.132 & 0.002 \\
\hline & {$[0.170]$} & {$[0.014]$} & {$[0.176]$} & {$[0.016]$} \\
\hline \multirow[t]{2}{*}{ sentence } & -0.063 & -0.001 & -0.013 & -0.001 \\
\hline & {$[0.056]$} & {$[0.006]$} & {$[0.063]$} & {$[0.006]$} \\
\hline $\mathrm{N}$ & 1006 & 1006 & 1006 & 1006 \\
\hline R-squared & 0.038 & 0.035 & 0.010 & 0.016 \\
\hline \multicolumn{5}{|l|}{ Panel B: With Controls } \\
\hline \multirow[t]{2}{*}{ Prevailing Sex Ratio } & $7.583^{* * *}$ & $0.470^{*}$ & $-4.758 * *$ & $0.629 * *$ \\
\hline & {$[2.615]$} & {$[0.280]$} & {$[2.171]$} & {$[0.255]$} \\
\hline \multirow[t]{2}{*}{ Time spent in prison } & -0.013 & 0.002 & 0.137 & 0.004 \\
\hline & {$[0.171]$} & {$[0.014]$} & {$[0.177]$} & {$[0.016]$} \\
\hline \multirow[t]{2}{*}{ Total sentence length } & -0.054 & -.0001 & -0.016 & -0.001 \\
\hline & {$[0.057]$} & {$[0.006]$} & {$[0.062]$} & {$[0.005]$} \\
\hline \multirow[t]{2}{*}{ Age } & -0.035 & -0.003 & 0.028 & -0.003 \\
\hline & {$[0.026]$} & {$[0.003]$} & {$[0.027]$} & {$[0.003]$} \\
\hline \multirow[t]{2}{*}{ Years of schooling } & 0.071 & -0.004 & -0.064 & -0.003 \\
\hline & {$[0.058]$} & {$[0.006]$} & {$[0.053]$} & {$[0.006]$} \\
\hline \multirow[t]{2}{*}{ IQ test score } & 0.018 & -0.008 & -0.097 & 0.000 \\
\hline & {$[0.063]$} & {$[0.006]$} & {$[0.061]$} & {$[0.006]$} \\
\hline \multirow{2}{*}{ Married } & 0.391 & $0.060^{*}$ & 0.327 & -0.001 \\
\hline & {$[0.380]$} & {$[0.034]$} & {$[0.382]$} & {$[0.038]$} \\
\hline \multirow[t]{2}{*}{ Number of children } & $-0.357^{*}$ & -0.023 & -0.135 & 0.005 \\
\hline & {$[0.190]$} & {$[0.020]$} & {$[0.215]$} & {$[0.024]$} \\
\hline \multirow[t]{2}{*}{ Father's years of schooling } & -0.009 & -0.004 & -0.041 & -0.003 \\
\hline & {$[0.044]$} & {$[0.004]$} & {$[0.037]$} & {$[0.005]$} \\
\hline \multirow[t]{2}{*}{ Mother's years of schooling } & 0.021 & 0.003 & 0.028 & 0.004 \\
\hline & {$[0.038]$} & {$[0.004]$} & {$[0.038]$} & {$[0.005]$} \\
\hline \multirow[t]{2}{*}{ Log of Prefecture GDP } & -0.005 & $0.053^{*}$ & $-0.530^{*}$ & $0.058^{*}$ \\
\hline & {$[0.325]$} & {$[0.030]$} & {$[0.296]$} & {$[0.034]$} \\
\hline \multirow[t]{2}{*}{ Gini coefficient for the Pref. } & 0.847 & 0.224 & -3.943 & 0.114 \\
\hline & {$[3.680]$} & {$[0.302]$} & {$[2.840]$} & {$[0.328]$} \\
\hline \multirow[t]{2}{*}{ Out-migration rate } & 0.010 & -0.003 & 0.008 & -0.001 \\
\hline & {$[0.023]$} & {$[0.002]$} & {$[0.030]$} & {$[0.003]$} \\
\hline \multirow{2}{*}{ Minority population share } & 0.818 & 0.143 & $-1.606^{*}$ & $0.258^{* *}$ \\
\hline & {$[1.174]$} & {$[0.093]$} & {$[0.847]$} & {$[0.101]$} \\
\hline $\mathrm{N}$ & 1006 & 1006 & 1006 & 1006 \\
\hline R-squared & 0.054 & 0.049 & 0.027 & 0.028 \\
\hline
\end{tabular}

Notes: All specifications also control for prisoner as a correction for choice-based sampling, see Solon et al. (2015). All specifications include provincial fixed effects. Standard errors are clustered by prefecture.***indicates significance at $1 \%$ level, ** at $5 \%$ level, * at $10 \%$ level. 


\begin{tabular}{|c|l|l|}
\hline & \multicolumn{1}{|c|}{ A } & \multicolumn{1}{|c|}{ B } \\
\hline 1 & $\begin{array}{l}\text { To get 1000 Yuan after } \\
\text { one month }\end{array}$ & $\begin{array}{l}\text { To get 1025 Yuan after } \\
\text { seven months }\end{array}$ \\
\hline
\end{tabular}
\begin{tabular}{|c|l|l|}
\hline 2 & $\begin{array}{l}\text { To get } 1000 \text { Yuan after } \\
\text { one month }\end{array}$ & $\begin{array}{l}\text { To get } 1075 \text { Yuan after seven } \\
\text { months }\end{array}$ \\
\hline
\end{tabular}

\begin{tabular}{|c|c|c|}
\hline 3 & $\begin{array}{l}\text { To get } 1000 \text { Yuan after } \\
\text { one month }\end{array}$ & $\begin{array}{l}\text { To get } 1125 \text { Yuan after seven } \\
\text { months }\end{array}$ \\
\hline 4 & $\begin{array}{l}\text { To get } 1000 \text { Yuan after } \\
\text { one month }\end{array}$ & $\begin{array}{l}\text { To get } 1175 \text { Yuan after seven } \\
\text { months }\end{array}$ \\
\hline 5 & $\begin{array}{l}\text { To get } 1000 \text { Yuan after } \\
\text { one month }\end{array}$ & $\begin{array}{l}\text { To get } 1225 \text { Yuan after seven } \\
\text { months }\end{array}$ \\
\hline 6 & $\begin{array}{l}\text { To get } 1000 \text { Yuan after } \\
\text { one month }\end{array}$ & $\begin{array}{l}\text { To get } 1275 \text { Yuan after seven } \\
\text { months }\end{array}$ \\
\hline 7 & $\begin{array}{l}\text { To get } 1000 \text { Yuan after } \\
\text { one month }\end{array}$ & $\begin{array}{l}\text { To get } 1325 \text { Yuan after seven } \\
\text { months }\end{array}$ \\
\hline 8 & $\begin{array}{l}\text { To get } 1000 \text { Yuan after } \\
\text { one month }\end{array}$ & $\begin{array}{l}\text { To get } 1375 \text { Yuan after seven } \\
\text { months }\end{array}$ \\
\hline 9 & $\begin{array}{l}\text { To get } 1000 \text { Yuan after } \\
\text { one month }\end{array}$ & $\begin{array}{l}\text { To get } 1425 \text { Yuan after seven } \\
\text { months }\end{array}$ \\
\hline 10 & $\begin{array}{l}\text { To get } 1000 \text { Yuan after } \\
\text { one month }\end{array}$ & $\begin{array}{l}\text { To get } 1475 \text { Yuan after } \\
\text { seven months }\end{array}$ \\
\hline 11 & $\begin{array}{l}\text { To get } 1000 \text { Yuan after } \\
\text { one month }\end{array}$ & $\begin{array}{l}\text { To get } 1525 \text { Yuan after } \\
\text { seven months }\end{array}$ \\
\hline
\end{tabular}

Figure A1: Time Preference Choices 


\begin{tabular}{|c|c|c|}
\hline & Choice A & Choice B \\
\hline 1 & 45 Yuan for sure & $\begin{array}{l}60 \text { if you roll 1,2,3 } \\
0 \text { if you roll 4,5,6 }\end{array}$ \\
\hline 2 & 45 Yuan for sure & $\begin{array}{l}75 \text { if you roll 1,2,3 } \\
0 \text { if you roll 4,5,6 }\end{array}$ \\
\hline 3 & 45 Yuan for sure & $\begin{array}{l}90 \text { if you roll 1,2,3 } \\
0 \text { if you roll 4,5,6 }\end{array}$ \\
\hline 4 & 45 Yuan for sure & $\begin{array}{l}105 \text { if you roll } 1,2,3 \\
0 \text { if you roll } 4,5,6\end{array}$ \\
\hline 5 & 45 Yuan for sure & $\begin{array}{l}120 \text { if you roll 1,2,3 } \\
0 \text { if you roll 4,5,6 }\end{array}$ \\
\hline 6 & 45 Yuan for sure & $\begin{array}{l}135 \text { if you roll 1,2,3 } \\
0 \text { if you roll 4,5,6 }\end{array}$ \\
\hline 7 & 45 Yuan for sure & $\begin{array}{l}150 \text { if you roll 1,2,3 } \\
0 \text { if you roll 4,5,6 }\end{array}$ \\
\hline 8 & 45 Yuan for sure & $\begin{array}{l}165 \text { if you roll 1,2,3 } \\
0 \text { if you roll } 4,5,6\end{array}$ \\
\hline 9 & 45 Yuan for sure & $\begin{array}{l}180 \text { if you roll 1,2,3 } \\
0 \text { if you roll } 4,5,6\end{array}$ \\
\hline 10 & 45 Yuan for sure & $\begin{array}{l}195 \text { if you roll 1,2,3 } \\
0 \text { if you roll 4,5,6 }\end{array}$ \\
\hline 11 & 45 Yuan for sure & $\begin{array}{l}210 \text { if you roll } 1,2,3 \\
0 \text { if you roll } 4,5,6\end{array}$ \\
\hline
\end{tabular}

Figure A2: Risk Game Choices 

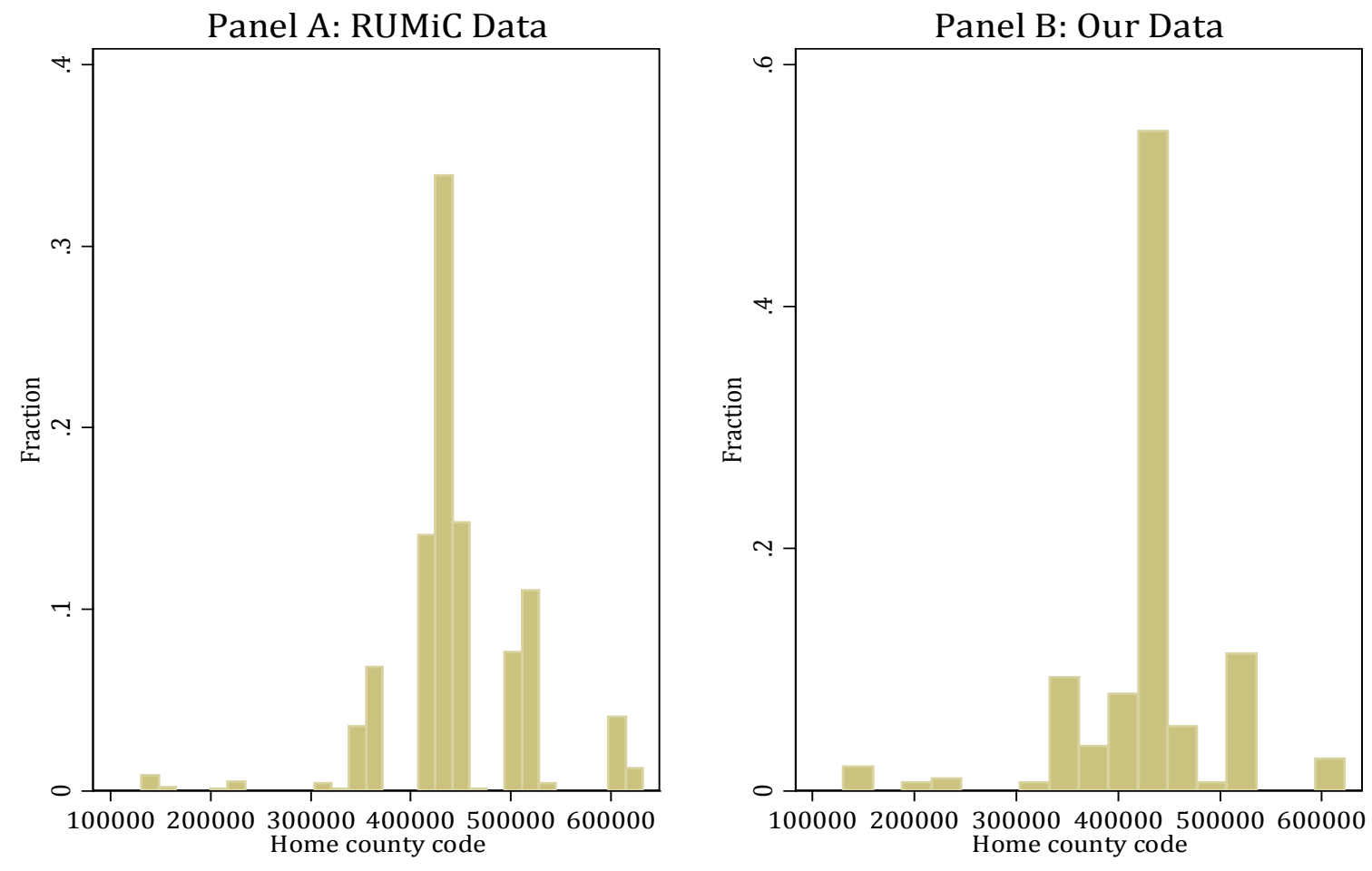

Figure A3: Comparison of Birth Counties of Our Non-inmate Sample with the RUMiC Sample 